DIVISION OF THE HUMANITIES AND SOCIAL SCIENCES

CALIFORNIA INSTITUTE OF TECHNOLOGY

PASADENA, CALIFORNIA 91125

ENDOGENOUS ENTRY AND SELF-SELECTION IN PRIVATE VALUE AUCTIONS: AN EXPERIMENTAL STUDY

Thomas R.Palfrey

California Institute of Technology

Svetlana Pevniskaya

Ohio State University

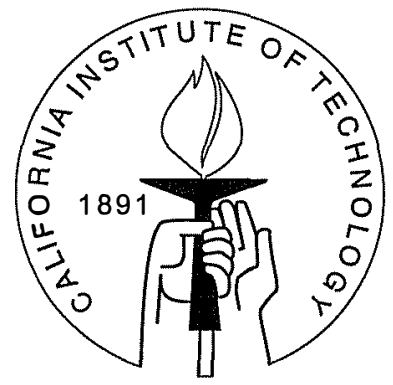

SOCIAL SCIENCE WORKING PAPER 1172

August 2003 


\title{
Endogenous Entry and Self-selection in Private Value Auctions: An Experimental Study*
}

\author{
Thomas R. Palfrey \\ California Institute of Technology
}

\author{
Svetlana Pevnitskaya \\ Ohio State University
}

February 2003

\begin{abstract}
This paper presents the results of an experimental study of endogenous entry and bidding behavior in first-price independent private value auctions. In the first stage $\mathrm{N}$ potential bidders simultaneously decide whether to participate in an auction or to claim a fixed outside option. At this stage all potential bidders know $\mathrm{N}$, the distribution of possible values, and the value of the outside option. In the second stage, each entering bidder submits a bid after learning their own private value for the object and the number of entering bidders. We find evidence of self-selection effect, as predicted by an equilibrium model of heterogeneous risk averse bidders. The theoretical model predicts that bidding in the auction will be lower with endogenous entry because only the less risk averse bidders will choose to enter. We also find that entry decreases with the value of the outside option, as predicted. One surprising finding is that we observe over-entry relative to the theoretical predictions.
\end{abstract}

Keywords: auctions, experimental economics, game theory

\footnotetext{
* We would like to thank Richard Day, W. Bentley MacLeod, John Morgan, Eric Talley, Quong Vuong, and seminar participants at Caltech, Ohio State University, Texas A \& M University, University of Southern California, and the 2000 meeting of the Economic Science Association for many helpful comments. Financial support was provided by the Hacker Social Science Experimental Laboratory and the National Science Foundation (SES-9631627 and SES0079301). We thank James Walker for sharing data. Direct correspondence to Svetlana Pevnitskaya, 410 Arps Hall, 1945 N. High Street, Columbus, OH 43210, svetlana@econ.ohio-state.edu.
} 


\section{Introduction}

This paper presents an experimental analysis of endogenous entry in first-price independent private value (IPV) auctions. Most of the experimental literature focuses on auctions with a fixed number of bidders (e.g., Cox, Robertson and Smith, 1982, Cox, Smith and Walker, 1988). There are two key findings in the data. The first is that bids are higher than predicted by an equilibrium theory of risk neutral bidders, which is consistent with risk aversion. The second is that there is significant heterogeneity, with some bidders bidding consistently higher than others.

A theoretical model with heterogeneous and privately known risk aversion parameters was developed by Cox, Smith, and Walker (1988), who fit their model to an experimental data set with considerable success. That proposed theoretical explanation, heterogeneous risk aversion, has additional interesting theoretical implications which can be directly tested. Specifically, Pevnitskaya (2001) identifies a self-selection effect that will arise with heterogeneity in preferences, if there is an entry choice before the auction occurs. In particular, more risk averse bidders choose not to enter, while more risk tolerant bidders choose to enter. This self-selection effect will result in lower bids compared to auctions with an exogenously fixed number of bidders. The strength of the self-selection effect is increasing in the opportunity cost of entry (Pevnitskaya, 2001).

This paper reports the results of an experiment to test whether this self-selection effect can be observed, and, if so, to measure the magnitude of the effect. The design of the experiment involves three main treatment variables: the distribution of private values, the value of the outside option, and the number of potential bidders. We also conduct a baseline treatment without an outside option. We find evidence of the self-selection effect in all treatments. Bids are consistently lower in the auctions with an outside option than in the baseline auctions, controlling for the number of bidders. There one surprising finding. There is over-entry to auctions in every treatment, compared to the equilibrium predictions. In fact, average profit from entering the auction is significantly less than the value of the outside option.

The model is presented in Section 2. The details of the experimental design are described in Section 3. Analysis of the data generated by the experiment is presented in Section 4 . In Section 5 , we compare our findings with the results from the auction experiments of Cox, Smith and Walker (1988) and results from other experiments that investigate endogenous entry in common value auctions (Cox, Dinkin, and Smith, 2001) and in abstract participation games (Goeree and Holt, 2000).

\section{The Model}

To motivate the experiment, this section compares the equilibrium model of entry with homogeneous risk averse bidders to the model with heterogeneous risk averse bidders. The model is taken from Pevnitskaya (2001), which is an extension of a paper by Levin and Smith (1994) to allow for bidder heterogeneity and risk aversion. A single item is offered to a group of $N$ potential bidders. The offering proceeds in two stages. In the first stage participants decide simultaneously whether to enter the auction or stay out and claim an outside option payoff $\omega$. Before making their entry choice all potential bidders know the distribution of private values, $G(v)$, which is identical for all bidders, and the number of potential bidders $N$. We assume that $G$ has a continuously differentiable density function $g$, which is strictly positive on the interval $[\underline{v}, \bar{v}]$. In the second stage, each participant $i$ 
who chose to enter, learns $n$, the number of entrants, and draws an independent private value, $v_{i}$, from the known distribution of valuations, $G$. A first price auction is then conducted, where the highest bidder wins the object and pays a price equal to his bid. A symmetric perfect Bayesian equilibrium strategy of this two-stage game is an $N+1-t u p l e,\left(q^{*},\left\{B_{n}^{*}(\cdot)\right\}_{n=1}^{N}\right)$ where $B_{n}^{*}(\cdot)$ is an equilibrium bidding function, mapping valuations into bids, for the auction game with $n$ entrants.

\subsection{Homogeneous Bidders}

The homogeneous bidder case corresponds to a situation where all bidders have the same utility function, $U(x)$, where $x$ is the payoff from the game. This payoff to bidder $i$ is either $\omega, 0$, or $v_{i}-b_{i}$, depending on whether $i$ chooses the outside option, enters and does not win, or enter and wins, respectively. Pevnitskaya (2001) characterizes the equilibrium of this two stage game, under the assumption that there is a unique symmetric equilibrium bidding function in the second stage of the game, for all $n=1, \ldots, N$. Denote by $U_{n}^{*}(v)$ the expected utility to an entrant in the (unique) $B_{n}^{*}$ equilibrium if she draws a value $v$, then the expected utility of entering is given by

$$
\sum_{n=1}^{N}\left[\left(\begin{array}{c}
N-1 \\
n-1
\end{array}\right)\left(q^{*}\right)^{n-1}\left(1-q^{*}\right)^{N-n} \int_{\underline{v}}^{\bar{v}} U_{n}^{*}(v) d G(v)\right]
$$

Hence a symmetric mixed strategy equilibrium of the entry stage, is any solution to the following equation:

$$
\sum_{n=1}^{N}\left[\left(\begin{array}{c}
N-1 \\
n-1
\end{array}\right)\left(q^{*}\right)^{n-1}\left(1-q^{*}\right)^{N-n} \int_{\underline{v}}^{\bar{v}} U_{n}^{*}(v) d G(v)\right]=U(\omega)
$$

That is, the ex ante expected utility of entering has to equal the utility of the outside option. For the rest of the paper we assume a uniform distribution of independent private values over $[0, \bar{v}] .{ }^{1}$

\subsubsection{Risk neutrality}

With this distributional assumption, the equilibrium condition can be expressed in closed form for several interesting special cases. First, if all bidders are risk neutral, then $U(x)=x, B_{n}^{*}(v)=\frac{n-1}{n} v$ and $U_{n}^{*}(v)=\frac{v^{n}}{n \bar{v}^{n-1}}$, so the condition reduces to:

$$
\sum_{n=1}^{N}\left[\left(\begin{array}{c}
N-1 \\
n-1
\end{array}\right)\left(q^{*}\right)^{n-1}\left(1-q^{*}\right)^{N-n} \frac{\bar{v}}{n^{2}+n}\right]=\omega
$$

With entry, there is a two stage game, where the bidders rationally anticipate bidding in the second stage, given any number of entrants. Thus, one solves for a sequential equilibrium. For the firstprice sealed-bid auction with independently and uniformly distributed private values from $[0, \bar{v}]$ and risk neutral bidders, the equilibrium condition in the first stage can be written as (2). For a given number of potential bidders, $N$, an upper bound, $\bar{v}$, and the outside option, $\omega$, the equilibrium defines the probability of entry, $q^{*}$, in the auction. This equilibrium probability is defined in a way that the ex ante expected profit from participating in the auction is equal to the outside option. Therefore in the experiment, if there are risk neutral subjects, we expect to observe that the average profit of participating in the auction is approximately equal to the outside option.

\footnotetext{
${ }^{1}$ The general case is treated in Pevnitskaya, 2001.
} 


\subsubsection{Risk Averse (CRRA) Bidders}

If bidders are risk averse, then they will bid higher in equilibrium. We consider the case of constant relative risk aversion (CRRA), where $U(x)=x^{r}, r>0$. The linear equilibrium bidding function is (see Cox, Robertson and Smith, 1982, Cox, Smith and Walker, 1988, etc.):

$$
B(v, r)=\frac{n-1}{n-1+r} v
$$

where $v$ is the private value of the bidder, $n$ is the number of bidders and $r$ is the risk tolerance parameter. It is easy to see that this function is decreasing in $r$. This implies that the equilibrium condition for a symmetric mixed strategy entry equilibrium, $q_{r}^{*}$, for homogeneous CRRA risk averse subjects is:

$$
\sum_{n=1}^{N}\left[\left(\begin{array}{c}
N-1 \\
n-1
\end{array}\right)\left(q_{r}^{*}\right)^{n-1}\left(1-q_{r}^{*}\right)^{N-n} \frac{\bar{v}^{r}}{n+r}\left(\frac{r}{n-1+r}\right)^{r}\right]=\omega^{r}
$$

The solution is unique for any given $r$, and the equilibrium probability of entry is increasing in $r$ (Pevnitskaya 2001). In particular, this implies that the observed entry frequency should be less than what is predicted by risk neutral model.

\subsection{Heterogenous Risk Aversion}

Cox, Smith and Walker (1988) offer evidence that there is heterogeneity in risk aversion in experimental auctions. We assume bidders have CRRA utility functions, where the individual risk tolerance parameter of bidder $i, r_{i}$, be independently identically distributed from continuous distribution $F$ over the interval $[\underline{r}, \bar{r}]$, where $\underline{r} \geq 0$. Each bidder knows her own risk tolerance parameter, but only knows the distribution of the others. Given any behavior by the other bidders, the optimal entry rule for a bidder is always a cutpoint. That is, a critical value of the risk aversion parameter, such that a bidder enters when $r_{i}$ is greater than this value and otherwise does not enter. Therefore a symmetric equilibrium is characterized by a common cutpoint rule, $r^{*}{ }^{2}$ In equilibrium, the probability of a potential entrant entering the auction is just the probability that this player's risk tolerance parameter is greater than $r^{*}$. Therefore, the entry equilibrium will have the property that a bidder will enter if $r_{i}$ is such that

$$
\sum_{n=1}^{N}\left[\left(\begin{array}{c}
N-1 \\
n-1
\end{array}\right)\left(1-F\left(r^{*}\right)\right)^{n-1}\left(F\left(r^{*}\right)\right)^{N-n} E\left[U_{i}\left(\pi^{*} \mid n, r_{i}, r^{*}\right)\right]\right]>U\left(\omega, r_{i}\right)
$$

where $E\left[U\left(\pi^{*} \mid n, r_{i}, r^{*}\right)\right]$ denotes the ex ante expected utility to bidder $i$ with coefficient $r_{i}$ in the Bayesian equilibrium an auction, conditional on exactly $n$ bidders whose risk tolerance parameter satisfy $r>r^{*}$. Similarly, a bidder will not enter if $r_{i}$ is such that

$$
\sum_{n=1}^{N}\left[\left(\begin{array}{c}
N-1 \\
n-1
\end{array}\right)\left(1-F\left(r^{*}\right)\right)^{n-1}\left(F\left(r^{*}\right)\right)^{N-n} E\left[U_{i}\left(\pi^{*} \mid n, r_{i}, r^{*}\right)\right]\right]<U\left(\omega, r_{i}\right)
$$

Thus the equilibrium is a cutoff value $r_{i}=r^{*}$ for which the above holds with equality. That is,

\footnotetext{
${ }^{2}$ The analysis in this section is based on Pevnitskaya (2001).
} 


$$
\sum_{n=1}^{N}\left[\left(\begin{array}{c}
N-1 \\
n-1
\end{array}\right)\left(1-F\left(r^{*}\right)\right)^{n-1}\left(F\left(r^{*}\right)\right)^{N-n} E\left[U_{i}\left(\pi^{*} \mid n, r^{*}, r^{*}\right)\right]\right]=U\left(\omega, r^{*}\right)
$$

Summarizing, in the entry stage, the equilibrium has only bidders with $r_{i}>r^{*}$ entering the auction, and potential bidders with $r_{i}<r^{*}$ opting out. Potential with $r_{i}=r^{*}$ are indifferent between entering the auction or staying out, but they are measure zero and therefore do not effect any of the calculations. ${ }^{3}$ Therefore bidding in auctions with endogenous participation should be less aggressive compared to the treatment with fixed-n auctions. We call this the bidder selection effect. The equilibrium cut-off strategy $r^{*}$ is unique and strictly increasing in $\omega$ (Pevnitskaya, 2001). Therefore, as the value of the riskless outside option increases, only relatively more risk tolerant subjects choose to enter the auction. If $\omega$ increases, then the selection effect becomes stronger, and bidding behavior should be less aggressive on average. That is, as $\omega$ increases, the expected (with respect to $r_{i}$ ) bid, conditional on value, is lower for every value. Our experimental design allows us to investigate the above results. The next section presents the experiment design and procedures.

\section{The Experiment and Experimental Design.}

\subsection{Hypotheses}

The experiment is designed to address the following hypotheses, based on theoretical predictions of the model of entry with heterogeneous risk averse bidders:

H1 Bidding functions become steeper as the number of entrants increases.

H2 The average profit from participating in the auction is greater than the outside option.

H3 Observed bidding is more aggressive than predicted by risk neutral model.

H4 Observed entry frequency is less than predicted by the risk-neutral model.

H5 The entry frequency is decreasing in $\omega$.

H6 Bidders exhibit heterogeneity in entry and bidding strategies.

H7 More risk tolerant subjects self select themselves to participate in the auction and therefore bidding is less aggressive than in the treatment with fixed $n$.

H8 As the outside option increases, bidding behavior becomes less aggressive.

As a reference point of the analysis, let us consider the predictions of risk-neutral model.

\footnotetext{
${ }^{3}$ The equilibrium is characterized by equation 7 as long as $r^{*}$ is interior, that is $r^{*} \in(\underline{r}, \bar{r})$. Boundary cases are also possible, when $r^{*}=\underline{r}$ and all subjects enter the auction (for example if $\omega=0$ ) or when $r^{*}=\bar{r}$ and all subjects choose to stay out (for example if $\omega>\bar{v}$ ). In these boundary cases, equation 7 does not hold with equality.
} 


\subsection{Experimental Design}

To compare the results of the model with actual decision making, we choose four different sets of parameters. The three parameters we varied were the number of potential bidders, $N$, the upper bound of the distribution of valuations, $\bar{v}^{4}$ and the value of the outside option, $\omega$. These parameters were chosen so that the risk neutral equilibrium entry probability, $q^{*}$, was equal to either 0.5 or 0.35. We refer to the first entry condition as "High" and the second as "Low" 5 The four sets of parameters obtained by calibrating the risk neutral model are presented in Table 1.

\begin{tabular}{|l|l|l|l|l|}
\hline Parameter set & $N$ & $v$ & $\omega$ & Entry Condition \\
\hline 1 & 6 & 691 & 62 & High \\
\hline 2 & 6 & 416 & 62 & Low \\
\hline 3 & 6 & 691 & 103 & Low \\
\hline 4 & 4 & 382 & 62 & High \\
\hline
\end{tabular}

Table 1. Parameter treatments (Units of $v$ and $\omega$ are experimental currency units.)

By creating an auction environment with the above parameters, it is possible to address hypotheses $H 1-H 8$. For example, by comparing parameter sets 1 and 2 we can identify the effect of the distribution of values and by comparing 1 and 3 we can find the effect of the outside option on bidder profits and entry. Set 4 allows us to analyze the effect of the number of potential bidders. The primary treatment variable is the entry condition, either "High" or "Low," which is manipulated by varying $N$, the upper bound $\bar{v}$, and the outside option $\omega$. Parameter sets 1 and 4 are high entry and parameter sets 2 and 3 are low entry. In addition, two sessions were conducted for fixed-n auctions, where there was no outside option and subjects do not make an entry decision. A secondary treatment variable, not shown in Table 1, is the subject pool. Half of the endogenous entry experiments were conducted using students from Pasadena City College (PCC) and half were conducted using students from Caltech (CIT). The fixed $-n$ auctions used only Caltech students. A total of 10 sessions were conducted for auctions with endogenous entry and 2 sessions for auctions with no entry choice, each consisting of 30 rounds. In sessions with no entry choice, 12 subjects were divided by the computer into groups of 2,3 or 4 , over a sequence of 30 rounds. Subjects were always told how many bidders there were in their group, before submitting bids. Table 2 presents the complete sequence and description of the sessions.

\begin{tabular}{|l|l|c|c|c|c|c|}
\hline Subjects & School & $N$ & $\omega$ & $v$ & Entry Condition & \# of Sessions \\
\hline 12 & PCC & 6 & 62 & 691 & High & 2 \\
\hline 12 & CIT & 6 & 62 & 691 & High & 2 \\
\hline 8 & PCC & 4 & 62 & 382 & High & 3 \\
\hline 12 & CIT & 6 & 62 & 416 & Low & 1 \\
\hline 12 & CIT & 6 & 103 & 691 & Low & 2 \\
\hline 12 & CIT & $2,3,4$ & NA & 691 & fixed- $n$ & 2 \\
\hline
\end{tabular}

Table 2. Parameter Values of Experimental Sessions

\footnotetext{
${ }^{4}$ In all sessions, $\underline{v}=0$.

${ }^{5}$ If bidders are risk averse, the Nash equilibrium entry frequencies are below .5 for both treatments.
} 


\subsection{Procedures}

The experimental sessions were conducted at the Hacker Social Science Experimental Laboratory (SSEL), California Institute of Technology, using interactive auction software. All sessions used volunteers from the population of students at the California Institute of Technology (CIT) and Pasadena City College (PCC). A student could participate in the experiment only once and in each session only subjects from a particular school were present.

After all subjects arrived, they were assigned randomly to computer terminals. Instructions were read aloud, and these instructions contained a complete description of the rules. The key points of the instructions and experiment protocol are presented next. ${ }^{6}$ Experiment record sheets were distributed, and subjects were required to record information about each round (values, number of entrants, etc.) as soon as they received that information. The experiments were conducted through computer terminals, and silence was maintained throughout the experiment, except during the instructions. A record of all information decisions in the experiment by all subjects was written onto a datafile. The rules were the following.

Each experiment consisted of a series of auctions that took place over 30 rounds. In each round, the subjects were randomly divided into 2 groups of equal size. These groups were re-drawn after every single round. A separate IPV auction was held for each group in each round.

In each round before the auction began, subjects were given the option to participate in their group's auction or not. If they chose not to participate, they received a fixed payoff for that round. If they chose to participate in an auction, they were then randomly assigned a private value for the object in the auction. Each entrant's value was an independent draw from a uniform distribution over a specified interval, which was publicly announced to the subjects, and was the same throughout the whole session. Also at this time (before they make a bid), subjects are also told exactly how many members of their group decided to participate in the auction. Entrants recorded this information and then submitted a bid through the computer network.

After all bidders submitted a bid, the highest bidder earned the difference between his value and his bid, and other bidders earned zero. In the event of a tie, the computer program randomly selected one of the high bidders. Non-bidders (who opted out of the auction in that round) earned the outside option. At the end of the round, everyone in a group (including those who chose not to enter) was told what the high bid was in their group's auction and how many subjects in their group chose to enter. After the instructions, there were two practice rounds to familiarize subjects with the graphical user interface on their computer. Subjects were also required to answer a brief comprehension quiz that covers the main points of the experimental rules. Each session lasted between one and one and one-half hours. When the experiment was over, subjects were paid in cash in private. Their earnings are determined by adding up the payoffs for each of the 30 rounds. In addition subjects were paid a $\$ 5.00$ show up fee for coming to the experiment. ${ }^{7}$

\footnotetext{
${ }^{6}$ Sample instructions of the experiment can be found in Appendix G.

${ }^{7} \mathrm{PCC}$ subjects received a $\$ 10$ showup fee, since they had to come from off campus. Showup fees were announced at the time subjects were invited to participate in the experiment.
} 


\section{Results}

Given our design, the results are based on data from 600 auctions with entry, conducted in 10 sessions with 108 different bidders, which provide 3240 individual entry observations, and a smaller number of bidding observations. In additions there are 120 auctions with "fixed-n", using an additional 24 subjects, which provide 720 individual bidding observations. Each subject participated in only one session. Four subsections below address particular aspects of our research results: bidding behavior; test of the self selection effect; heterogeneity; entry rates; earnings.

\subsection{Bidding Behavior and the Selection Effect}

This subsection first addresses hypotheses $H 1$ and $H 3$. These two hypotheses state that bidding functions become steeper as the number of entrants increases and that observed bidding should be more aggressive than predicted by risk neutral model. Both of these are hypotheses that have been supported in experiments elsewhere. The graphs of bidding behavior are presented in Appendix A. Data points in those figures are (value, bid) pairs. There is a 45 degree line (bid=value) and theoretical risk neutral bid line on every graph. One can see quite clearly two things in this graph. First, the correlation of bids and value is very high. There are just a few outliers, corresponding to bids over value or zero (or nearly zero) bids. Second, the relationship between bids and values is nearly linear, with the slope increasing for larger numbers of bidders. Third, and somewhat less obvious, there is a slight nonlinearity for higher values. Specifically, bidders with very high values tend to bid a slightly smaller fraction of value than bidders with lower values.

All three of these features of bidding behavior are consistent with the theoretical model of heterogeneous risk aversion. In particular, the declining slope for high values is a feature that is predicted by that theoretical model. ${ }^{8}$ In particular, the nonlinearity indicates that a simple regression of all bids on all values will produce biased estimates of the bidding function. The recommended correction (Kagel, 1995) is to truncate the sample at the maximum value that would be in range of bids for any risk averse bidder. With $n$ bidders, this requires dropping all observations for which $v_{i}>\frac{n-1}{n} \bar{v}$. The theory predicts that equilibrium bid functions are linear in this range. The results of this estimation, with value truncation, are shown in Table 3, for each of the treatments, each subject pool, and for each number of entering bidders. ${ }^{9}$ That table displays, for each case, the estimated slope of the bidding function and the standard error of the estimate. ${ }^{10}$

\begin{tabular}{|l|l|l|l|l|l|}
\hline $\mathrm{n}$ & 12 CIT High & 12 CIT Low & 12 PCC High & 8 PCC High & Fixed-n \\
\hline 2 & $.68(.047)$ & $.53(.054)$ & $.71(.105)$ & $.64(.049)$ & $.80(.029)$ \\
\hline 3 & $.83(.042)$ & $.71(.025)$ & $.83(.038)$ & $.71(.031)$ & $.87(.018)$ \\
\hline 4 & $.87(.022)$ & $.78(.023)$ & $.73(.029)$ & $.69(.043)$ & $.87(.020)$ \\
\hline 5 & $.89(.020)$ & $.81(.075)$ & $.81(.048)$ & no data & no data \\
\hline 6 & $.95(.048)$ & $.51(.159)^{*}$ & $.88(.042)$ & no data & no data \\
\hline
\end{tabular}

Table 3. Slope estimates (*based on only 8 observations)

\footnotetext{
${ }^{8}$ See Kagel (1995).

${ }^{9}$ See appendix for additional details.

${ }^{10}$ Observation with zero bids and with bid exceeding value are also excluded.
} 
According to hypothesis $H 7$ in section 3 , after entry more risk tolerant subjects will self select themselves to participate in the auction and therefore the estimated slopes of bidding functions should be less than in the treatment with fixed $n$. This is clearly borne out in the data. For fixed $n$, we only have data with $n=2,3,4$. But for all 12 comparisons between the different entry conditions or subject pools and the fixed $n$ trials, the estimated slopes in the entry condition is less than or equal to the slopes with fixed $n$. Second, according to hypothesis $H 8$, as the outside option increases, more risk averse bidders self-select themselves out of the auction and therefore bidding slopes are predicted to be lower in the Low Entry condition than in the High Entry condition. From table 3 one can see that this was indeed the case for all numbers of entering bidders for the Caltech subject pool (there is no Low Entry treatment for PCC pool). Some, but not all of these comparisons are significant at the $95 \%$ confidence level. Overall, the data supports both predictions about a self-selection effect. We conclude that subjects who enter the auction are, on average, more risk tolerant.

It is also clear from Table 3 that bidding slopes tend to increase with the number of bidders, although this does not happen as much as would be predicted by the theory. In our data, bidder responsiveness to the number of entrants is weaker than expected, although there is a clear trend in the direction of higher bids with larger $n$. This lack of sensitivity to the number of bidders is most noticeable in the 8 PCC High sessions. ${ }^{11}$ Thus the data provides qualified support for Hypothesis $H 1$. Risk neutrality (i.e. $b=\frac{n-1}{n} v$ ) is easily rejected for the fixed $n$ data, and even for most of the individual cells in table 3. The exceptions are the PCC data with four bidders and endogenous entry, and the Low Entry Caltech data for $n=6$. However, in the latter case there were only 8 observations. Thus, $H 3$ is supported in most, but not all treatments.

\subsection{Entry}

This subsection of the paper analyses the predictions of hypothesis $H 4$, which states that the observed entry frequency should be less than predicted by risk-neutral model in Table 1. Also as the outside option increases, The entry frequency in treatment 3 should be less than entry frequency in treatment 1 . Table 4 below gives a summary of the entry rates for each treatment.

\begin{tabular}{|l|l|l|}
\hline & High Entry & Low Entry \\
\hline 12 subjects & $\begin{array}{l}\text { CIT: } 0.61(\mathrm{~N}=720) \\
\text { PCC: } 0.59(\mathrm{~N}=720)\end{array}$ & CIT: $0.45(\mathrm{~N}=1080)$ \\
\hline 8 subjects & PCC: $0.64(\mathrm{~N}=720)$ & \\
\hline
\end{tabular}

Table 4. Entry rates

We conducted 3 sessions with 8 subjects to generate the same number of observations as 2 sessions with 12 subjects. The table shows that there was substantial over-entry in every treatment (and in every session) relative to the risk neutral model predictions of 0.5 for the High Entry sessions and 0.35 for the Low Entry sessions. Hence we reject hypothesis H4. Comparing the 12 subjects

\footnotetext{
${ }^{11}$ The fact that bidding does not respond to the number of bidders exactly as theory would predict has been observed in the past. See for example Kagel (1995, pp. 514-15). As far as we know, this anomaly has not been explained.
} 
CIT treatments (first row in the table) we can see that over-entry is approximately of the same magnitude for High and Low sessions. Comparing the High PCC treatments (first column in the table) we can see that there was slightly more over entry when there were fewer potential entrants. Although there is significantly $(p<.01)$ more entry than predicted by a risk-neutral model, the entry frequency dropped by 0.16 in treatment 3 compared to treatment 1 , which is also statistically significant $(p<.01)$. Thus, $H 4$ is rejected, but $H 5$ is supported by the data. Over time entry frequency is slowly declining towards equilibrium as shown in the figures in Appendix F. Based on a linear regression of entry frequency on time, the slope is negative for all four conditions in the experiments, and is significant $(\mathrm{p}<.02)$ for the three High Entry conditions. ${ }^{12}$

\subsection{Heterogeneity}

This section looks at evidence for heterogeneity across bidders and addresses hypothesis $H 6$. The data shows strong evidence of heterogeneity among subjects, that can be observed through bidding and entry behavior. Table 5 shows the frequency of inefficient allocations, i.e. auctions where the bidder with highest value does not win the auction.

\begin{tabular}{|l|l|l|}
\hline & High Entry & Low Entry \\
\hline \multirow{2}{*}{6 subjects } & $\begin{array}{l}\text { CIT: } 7.7 \%(8.5 \%) \\
\text { PCC: } 18.1 \%(23.3 \%)\end{array}$ & CIT: $13 \%(13 \%)$ \\
\hline 4 subjects & PCC: $16.3 \%(16.9 \%)$ & \\
\hline
\end{tabular}

Table 5. Inefficient allocations

The percentage of auctions with inefficient allocations was obtained after removing bids that were greater than the value. The actual percentage without such trimming is shown in the brackets. There is heterogeneity in bidding in all treatments. The heterogeneity can also be observed in entry decisions. Figure 1 below presents the data on the frequency of entry of individual subjects for Caltech sessions. The graphs for other sessions are shown in Appendix C.

There are two spikes at 0 and 30, which supports the prediction of the model that some subjects will always choose to stay out and other always enter, based on their risk aversion parameter, which is clearly indicative of heterogeneity. The results of Pearson tests are presented in the table in Appendix E. We test the hypotheses whether the observed distribution of entry frequencies (across subjects) is consistent with a random binomial process that is the same for all subjects. Each observation is an integer between 0 and 30, corresponding to the number of times a subject can enter the auction during the 30 round experiment. The hypothesis that the data is generated by independent draws from the same binomial distribution over 31 categories is easily rejected at any conventional significance level. Our test statistic is the Pearson statistic, which is given by the sum of criterion values in the table over 31 categories). In Appendix E, the first line in the table shows the mean entry rate for the tested binomial distribution and the range of categories (frequencies) in the test. For example 10-20 means that we fit data only for subjects who entered the auction

\footnotetext{
${ }^{12}$ The figures in Appendix $\mathrm{F}$ also show the fitted regression lines for each treatment.
} 


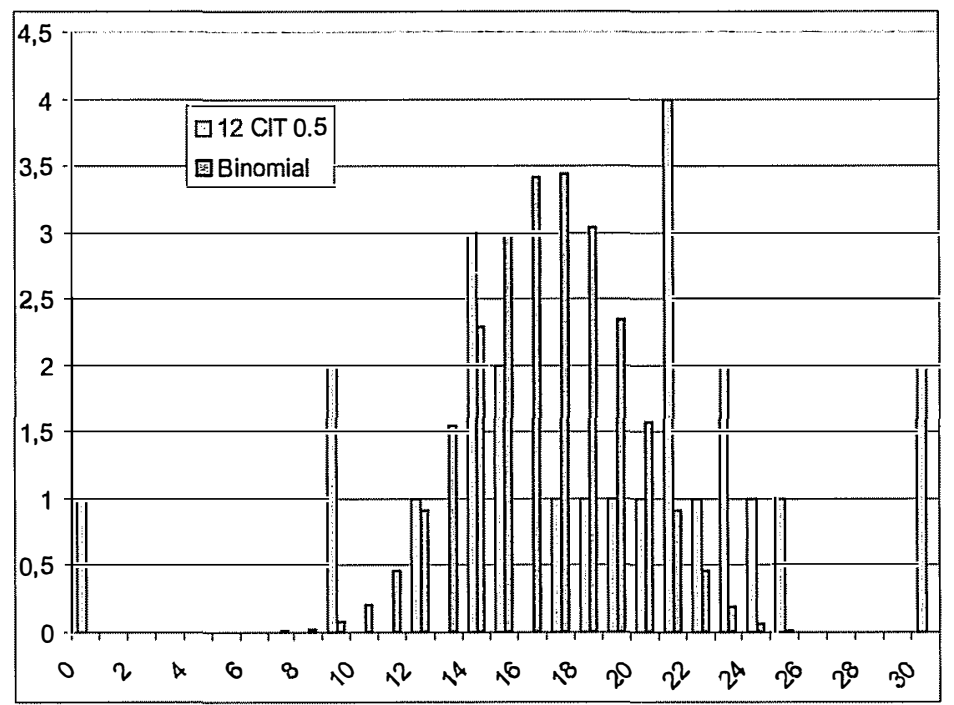

Figure 1: Number of subjects over how many times they entered the auction.

between 10 and 20 times. ${ }^{13}$ The second row presents treatment name, the third row shows Pearson statistics, and the fourth row shows the confidence level. As can be observed in the table, we reject the hypothesis of binomial approximation. The data supports the hypothesis that there is heterogeneity in entry and bidding. Thus, we find strong support for the heterogeneity hypothesis, H6.

\subsection{Bidder Profit}

According to hypothesis $H 2$, the average profit from participating in the auction is greater than the outside option for risk averse subjects (and approximately equal to the outside option for risk neutral subjects). Given over-entry to the auction, the average profits from entering the auction are actually lower than the value of the outside option. The graphs in Figures 2 and 3 present profit data from the experiment.

Figure 2 shows actual average profit from entering and the outside option. With surprising consistency in every treatment, subjects forego nearly half of their possible profit by entering the auction. We reject hypothesis $H 2$. Appendix B shows actual and expected profits in auctions for different numbers of bidders in each treatment. For auctions with $n=2$ or greater the profits of entering are consistently less than predicted by the model. The graph in Figure 3 presents profits in different treatments.

\footnotetext{
${ }^{13}$ If we included all categories, the hypothesis is almost trivially rejected, since we have observations in the tail. Our test shows that there is significant heterogeneity even among the bidders who enter between $1 / 3$ and $2 / 3$ of the time.
} 


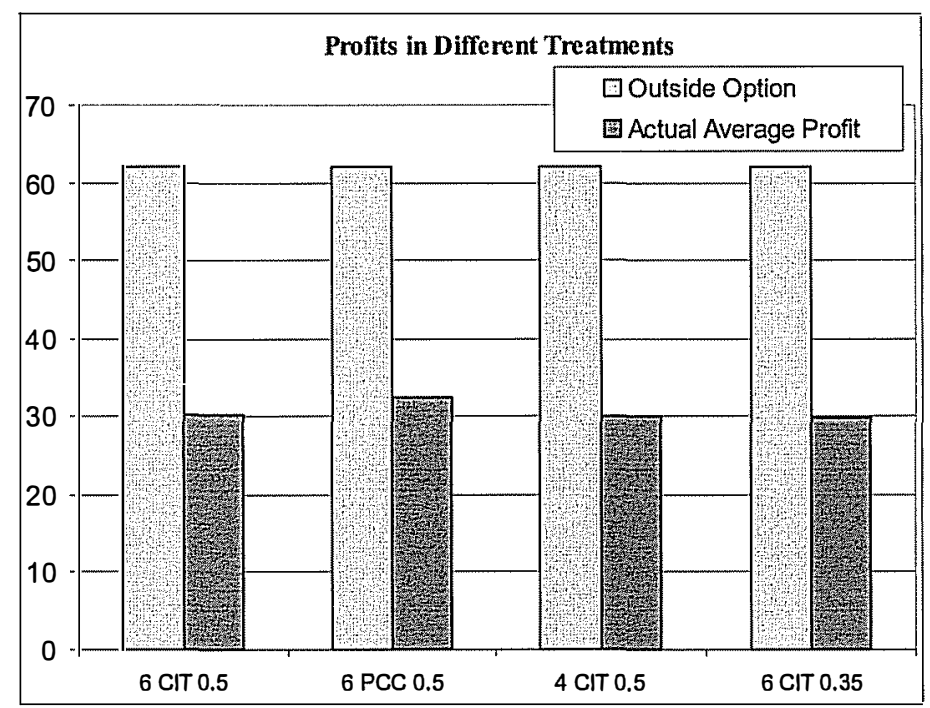

Figure 2: Profits

It is shown that as the number of potential bidders decreases, the average profit from participating in the auction goes down (compare 12 PCC 0.5 and 8 PCC 0.5). Also average profit in the auction decreased when the entry probability was lowered (compare 12 CIT 0.5 and 12 CIT 0.35 ). Low profits are directly related to the over-entry phenomena. Greater entry generates auctions with higher numbers of bidders, leading to lower profits, on average, for the bidders. For example in the treatment with 8 PCC subjects, the entry frequencies (and over-entry) are highest and the profits are lowest. Therefore, one would expect bidders to enter less frequently as they gain experience in the environment. This happens, as noted in the previous section, but very slowly. We conjecture that this is due to rather limited feedback and the fact that their entry decisions are randomly reinforced. ${ }^{14}$

\section{Comparison to other results}

An experiment in private value auctions with a fixed number of bidders was reported in Cox, Smith and Walker, 1988 (CSW). That experiment had sessions for both inexperienced and experienced subjects. Since in this research subjects participated only once, we focus attention only on their data for inexperienced subjects. They have observations of bidding in auctions with $3,4,5,6$, and 9 bidders with uniformly distributed values in all cases. In all of their auctions, the number of bidders in the auction remained fixed over all rounds. In addition, there was no random matching protocol,

\footnotetext{
${ }^{14}$ The difference between random versus deterministic reinforcement is a major theme in the operant conditioning literature. See, for example, Reese (1966) and Reynolds (1975), for a discussion of experiments showing that random reinforcement produces more persitent behavior and slower learning compared equivalent levels of non-random reinforcement.
} 


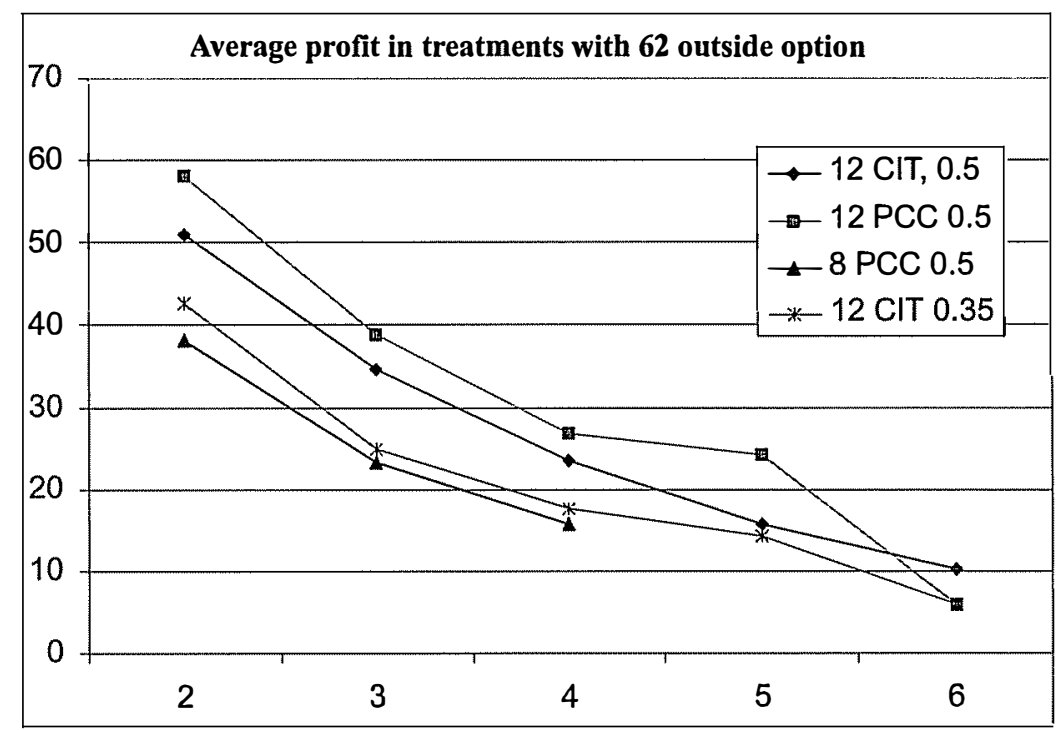

Figure 3: Average Profits in Different Treatments

so in each session the same set of $n$ bidders competed repeatedly against each other, drawing a new valuation for each different auction. Since the set up of the CSW experiment belongs to fixed-n design, the bidding should be more aggressive than in our endogenous entry treatments, because there is no selection effect. We estimated the slopes of an aggregate bidding functions for their data, which are shown in Table 6 . As before, we truncate the high valuation observations to avoid the problem of nonlinear bid functions. The last column of Table 6 gives the theoretical slope of the bidding function in the homogeneous risk aversion model with $r=0.5$. The first and second column gives the estimates from our endogenous entry data and our "no entry choice" data, respectively.

\begin{tabular}{|l|l|l|l|l|}
\hline $\mathrm{n}$ & Entry choice & Fixed-n (CIT) & Fixed-n (CSW) & theoretical $r=.5$ \\
\hline 2 & $.64(.030)$ & $.80(.029)$ & no data & .67 \\
\hline 3 & $.78(.015)$ & $.87(.018)$ & $.74(.017)$ & .80 \\
\hline 4 & $.80(.013)$ & $.87(.020)$ & $.91(.009)$ & .86 \\
\hline 5 & $.79(.019)$ & no data & $.95(.015)$ & .89 \\
\hline 6 & $.87(.019)$ & no data & $.87(.012)$ & .91 \\
\hline
\end{tabular}

Table 6. Comparison with CSW data

Bids are lower in the endogenous entry treatments than in the in fixed-n treatments for all $n$, in both the CIT and CSW data, with the exception of the CSW data for $n=3 .{ }^{15}$ Bids were also lower than the theoretical equilibrium bids for the model of homogeneous risk averse bidders, evaluated for $r=.5$, which is approximately what is estimated in Goeree, Holt, and Palfrey (2002). Bidders in

\footnotetext{
${ }^{15} \mathrm{CSW}$ conjecture that their low slope estimate for $n=3$ was due to an unusual feature of their design. It is also possible that there was some collusion, since their design used repeated auctions with the same group of 3 subjects.
} 
sessions with a fixed number of participants in the auction are responsive to the number of bidders, with the one exception being in the CSW data, where the bidding slope with $n=5$ is higher than the bidding slope with $n=6$. To our knowledge, this anomaly has never been explained, except possibly as a statistical artifact. ${ }^{16}$

The most surprising result of this paper is the observation of systematic over-entry. There is mixed evidence from other experiments. Looking at data from a variety of different entry games, Goeree and Holt (2000) find that if the Nash equilibrium probability of entry is below .5 there tends to be over-entry relative to the Nash equilibrium. They prove that this can be accounted for theoretically by quantal response equilibrium (McKelvey and Palfrey 1995). In our design, since bidders are risk averse, then the Nash equilibrium probability of entry is below .5 for both our low entry and high entry treatments. Thus, over-entry in our data is consistent with data from these other experiments and is consistent with the direction of theoretical predictions of quantal response equilibrium. Second, our observation of over-entry is the opposite of what was found in an experimental study on entry in common value auctions by Cox, Dinkin and Smith (2001), where they observed under-entry relative to the risk neutral prediction. This may seem contradictory, but in fact it is consistent with the Goeree and Holt's (2000) quantal response equilibrium predictions. The reason is that in all of the common value entry experiments, the predicted entry rates were greater than .5. Goeree and Holt's results suggest that in this case one would expect under-entry relative to the Nash equilibrium. Thus quantal response equilibrium can explain simultaneously the qualitative findings of over-entry in our experiment and under-entry in Cox, Dinkin and Smith (2001). ${ }^{17}$

Another possible explanation that has been suggested to us is based on relative payoff utility functions. For example Morgan, Steiglitz and Reis, 2001, examine a standard independent private value model, but assume that subjects maximize the weighted difference between their own expected payoff and the expected payoff of the rival. In this setup subjects could enter the auction to "cutdown" profits of other participants. While we have not worked out the theoretical details, it is conceivable that this could lead to over-entry. However, their model is inconsistent with our strong self-selection results. The reason is that a heterogeneous version of their rivalistic model would also yield a selection effect, but one that works in the opposite direction. That is, more rivalistic bidders would tend to enter, generating more aggressive bidding, and less rivalistic bidders would opt for the outside option. This would lead to a reversal of hypothesis $H 7$, which is not consistent with our findings.

Yet another explanation might be that subjects obtain utility directly from participating in the auction, simply because not participating is less interesting. However, this explanation would be inconsistent with under-entry observed in Cox, Dinkin and Smith (2001) as well as the laboratory data on entry games cited in Goeree and Holt (2000).

\footnotetext{
${ }^{16}$ Kagel (1995) also points out this reversal (based on the analysis of individual bidding function), but offers no explanation.

${ }^{17}$ However, quantal response equilibrium cannot account for the finding that entry frequencies are greater than .5 in our high entry treatment.
} 


\section{Conclusions}

This paper presented an experimental study of endogenous entry in first price independent private value auctions. The main objective of the paper was to test whether there is a self selection effect that implies lower bidding if there is endogenous entry, compared to standard models that assume exogenous entry. To the extent there is such an effect, it could have important implications for auction design, the use of entry fees, competition between auctions and retail (fixed) pricing mechanisms, and so forth.

The key finding from our experiment is that the data support the self selection hypotheses. In all treatments with endogenous entry, entering bidders bid less aggressively, when compared to bidders in auctions with fixed number of participants. The experimental design addresses several other hypotheses. One of the treatments allowed us to investigate the effect of increasing the outside option on entry choice. The results of this treatment are consistent with the theoretical prediction that the "cut-off" value of the risk tolerance parameter increases with the outside option. It was consistent in two different ways: (1) entry frequency decreased; and (2) bidding became less aggressive than with a lower outside option. The number of potential bidders had no apparent effect on bidding if balanced by the upper bound of values. This is also consistent with the selection effect. The paper shows evidence of heterogeneity in entry decisions and bidding. A surprising result of this study, which occurred in every treatment, is over-entry compared to predictions of both the risk averse and the risk neutral models. In contrast, under-entry has been observed in some entry games and in a recent experiment on endogenous entry in common value auctions. These apparently contradictory findings are qualitatively consistent with quantal response equilibrium, which predicts over-entry when the Nash equilibrium entry frequencies are below .5 and under-entry when the Nash equilibrium entry frequencies are above .5. However, the magnitude of over-entry in our experiment is sufficiently great that it cannot be fully explained by quantal response equilibrium. Some additional factor must be present to explain entry frequencies above .5. Additional experimentation of equilibrium entry in different economic and game-theoretic contexts may be helpful in leading eventually to a more complete explanation of this phenomenon. 


\section{References}

[1] Cox, James C., Sam Dinkin and Vernon L. Smith (2001) Endogenous Entry and Exit in Common Value Auctions. Experimental Economics, 4:163-82.

[2] Cox, James C., Bruce Robertson and Vernon L. Smith (1982) Theory and Behavior of Single Object Auctions. Research in Experimental Economics, Editor: Vernon L. Smith, Volume 2.

[3] Cox, James C., Vernon L. Smith and James M. Walker (1988) Theory and Individual Behavior of First-Price Auctions. Journal of Risk and Uncertainty, 1:61-99.

[4] Cox, James C., Vernon L. Smith, and James M. Walker (1992) Theory and Misbehavior of First-Price Auctions: Comment, American Economic Review, 82, 1392-1412.

[5] Friedman, Daniel (1992) Theory and Misbehavior of First-Price Auctions: Comment, American Economic Review, 82(5), December, 1374-1378.

[6] Goeree, Jacob K. and Charles A. Holt (2000) An Explanation of Anomalous Behavior in Binary-Choice Games: Entry, Voting, Public Goods, and the Volunteers' Dilemma. University of Virginia Working Paper, January.

[7] Goeree, Jacob K. and Charles A. Holt and Thomas R. Palfrey (2002) Quantal Response Equilibrium and Overbidding in Private Value Auctions. Journal of Economic Theory, 104(1), 247-272.

[8] Harrison, Glenn W. (1989) Theory and Misbehavior of First-Price Auctions: Reply, American Economic Review, 82, 1426-43.

[9] Harrison, Glenn W. (1992) Theory and Misbehavior of First-Price Auctions, American Economic Review, 79, 749-762.

[10] Harstad, Ronald M., John H. Kagel and Dan Levin (1990) Equilibrium Bid Functions for Auctions with an Uncertain Number of Bidders. Economic Letters 33: 35-40.

[11] Kagel, John H. (1992) Auctions: A Survey of Current Research. In J.H. Kagel and A.E.Roth (eds.), The Handbook of Experimental Economics, Princeton: Princeton University Press.

[12] Kagel, John H. and Alvin E. Roth (1992) Theory and Misbehavior of First-Price Auctions: Comment, American Economic Review, 82, 1379-1391.

[13] Levin, Dan and James L. Smith (1994) Equilibrium in Auctions with Entry. American Economic Review, Volume 84, Issue 3, June: 585-599

[14] McAfee, R. Preston and John McMillan (1987a) Auctions with Entry. Economic Letters 23: 343-347.

[15] McAfee, R. Preston and John McMillan (1987b) Auctions with a Stochastic Number of Bidders. Journal of Economic Theory 43: 1-19. 
[16] McKelvey, Richard D. and Thomas R. Palfrey (1995) Quantal Response Equilibrium for Normal Form Games. Games and Economic Behavior, 10, 6-38.

[17] Merlo, Antonio and Andrew Schotter (1992) Theory and Misbehavior of First-Price Auctions; Comment, American Economic Review, 82(5), December, 1413-1425.

[18] Morgan, John, Ken Steiglitz and George Reis (2001) Relative Profit Auctions. Princeton University Working Paper, August.

[19] Pevnitskaya, Svetlana (2001) First-Price Private Value Auctions with an Endogenous Number of Heterogenous Bidders, University of Southern California.

[20] Reese, E.P. (1966) The Analysis of Human Operant Behavior. Dubuque, IA: Brown.

[21] Reynolds, G.S. (1975) A Primer of Operant Conditioning. Scott, Foresman and Company.

[22] Smith, James and Dan Levin (2001) Entry Coordination in Auctions and Social Welfare: An Experimental Investigation. International Journal of Game Theory, 30:321-350. 


\section{Appendix A. Bidding Data.}

A. 1. PCC subjects, $N=4, q=0.5$. ("RNNE bid" is risk neutral Nash equilibrium bid)

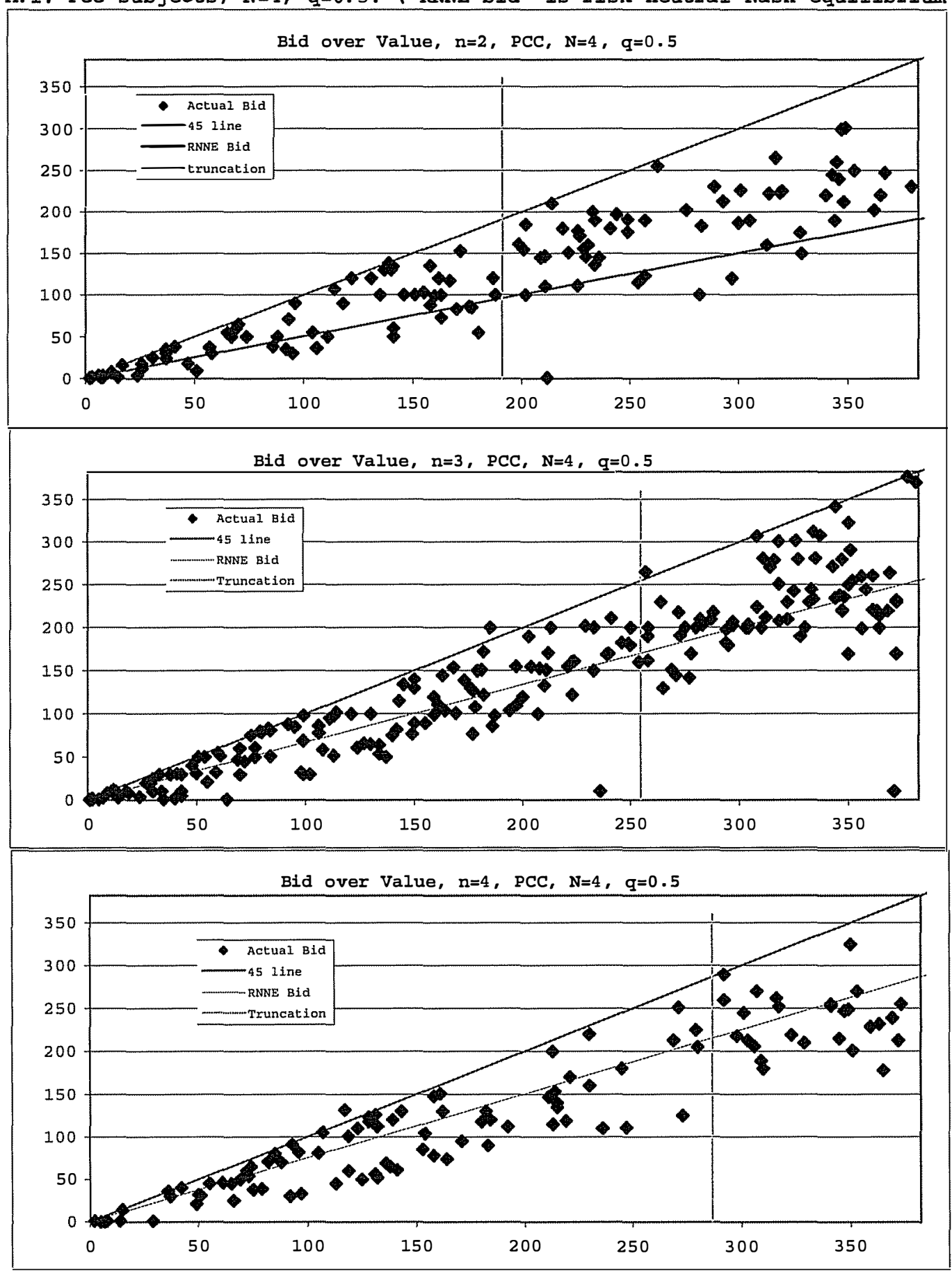


A.2. $P C C$ subjects, $N=6, q=0.5$.
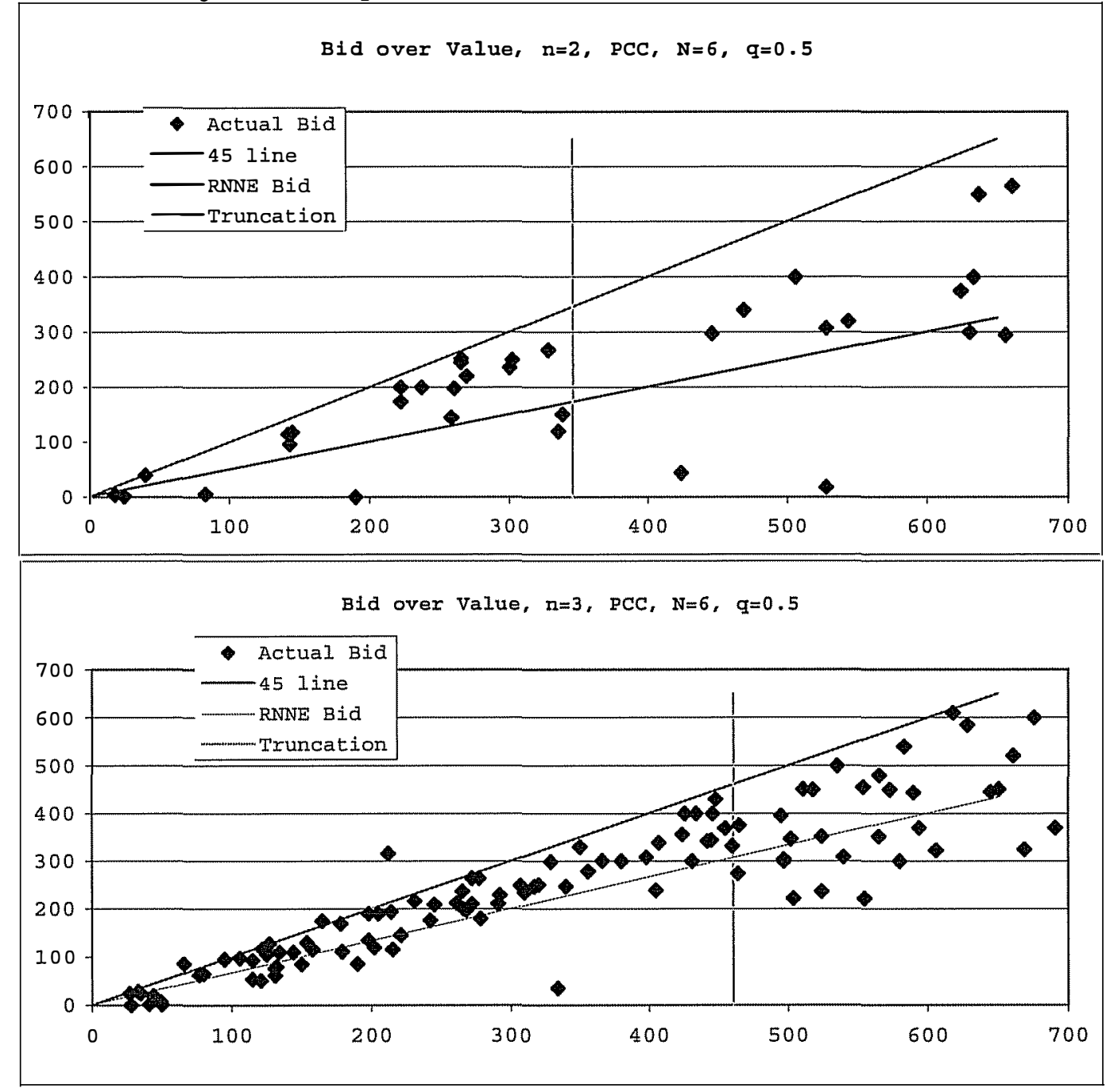
A.2. PCC subjects, $N=6, q=0.5$ (continued).
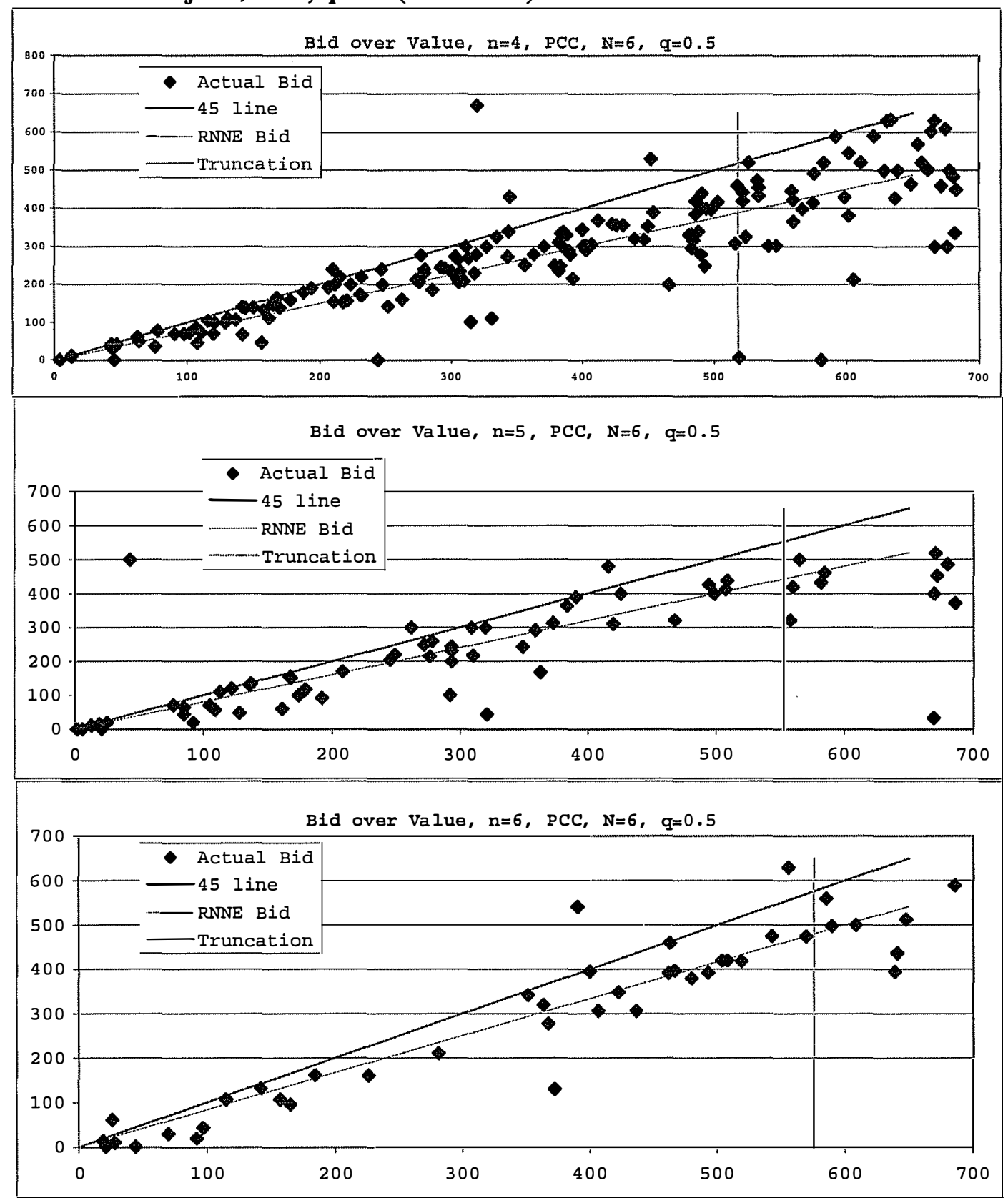
A.3. CIT subjects, $\mathrm{N}=6, \mathrm{q}=\mathbf{0 . 5}$.

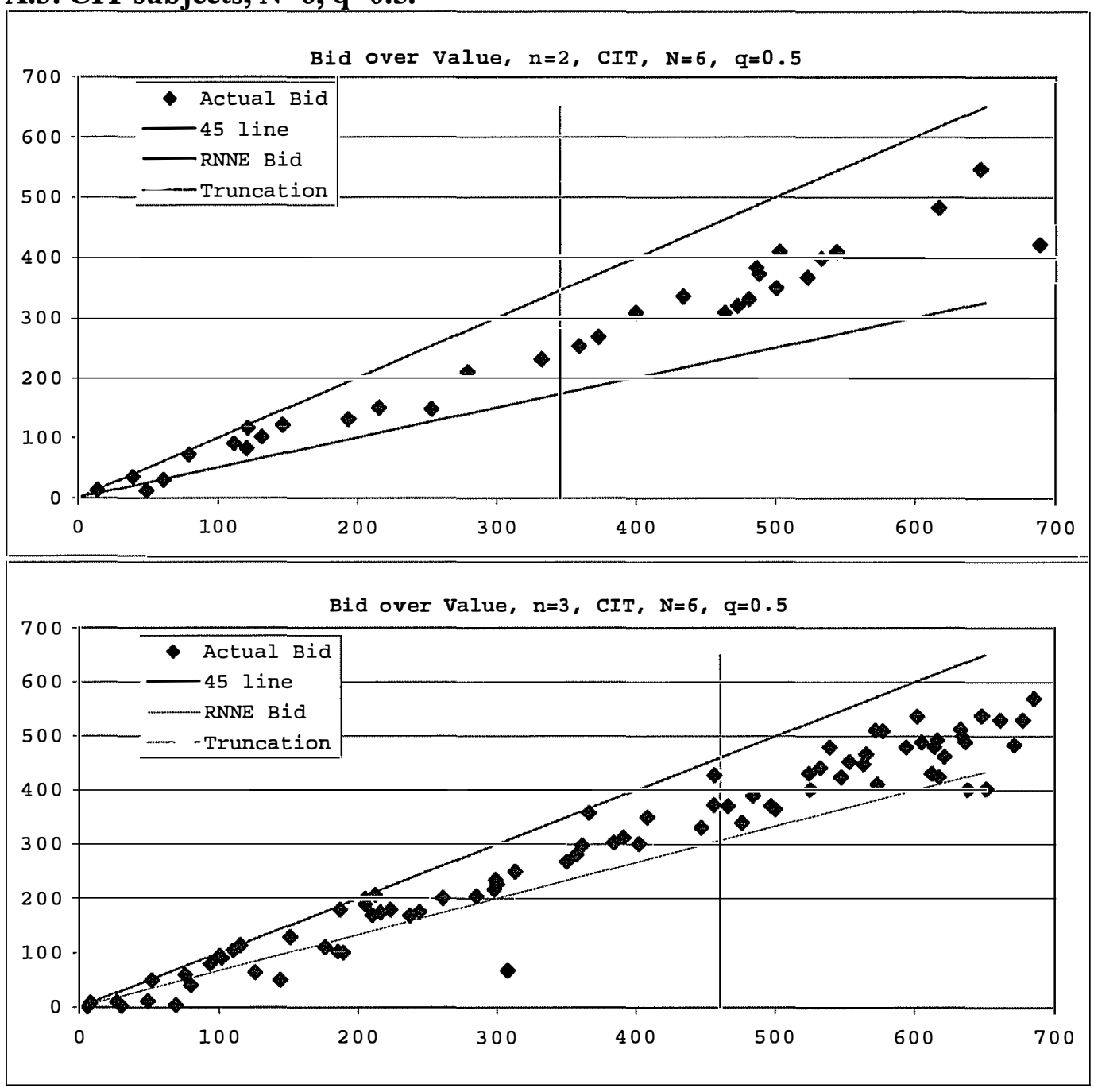




\section{A.3. CIT subjects, $\mathrm{N}=6, \mathrm{q}=\mathbf{0 . 5}$ (continued).}
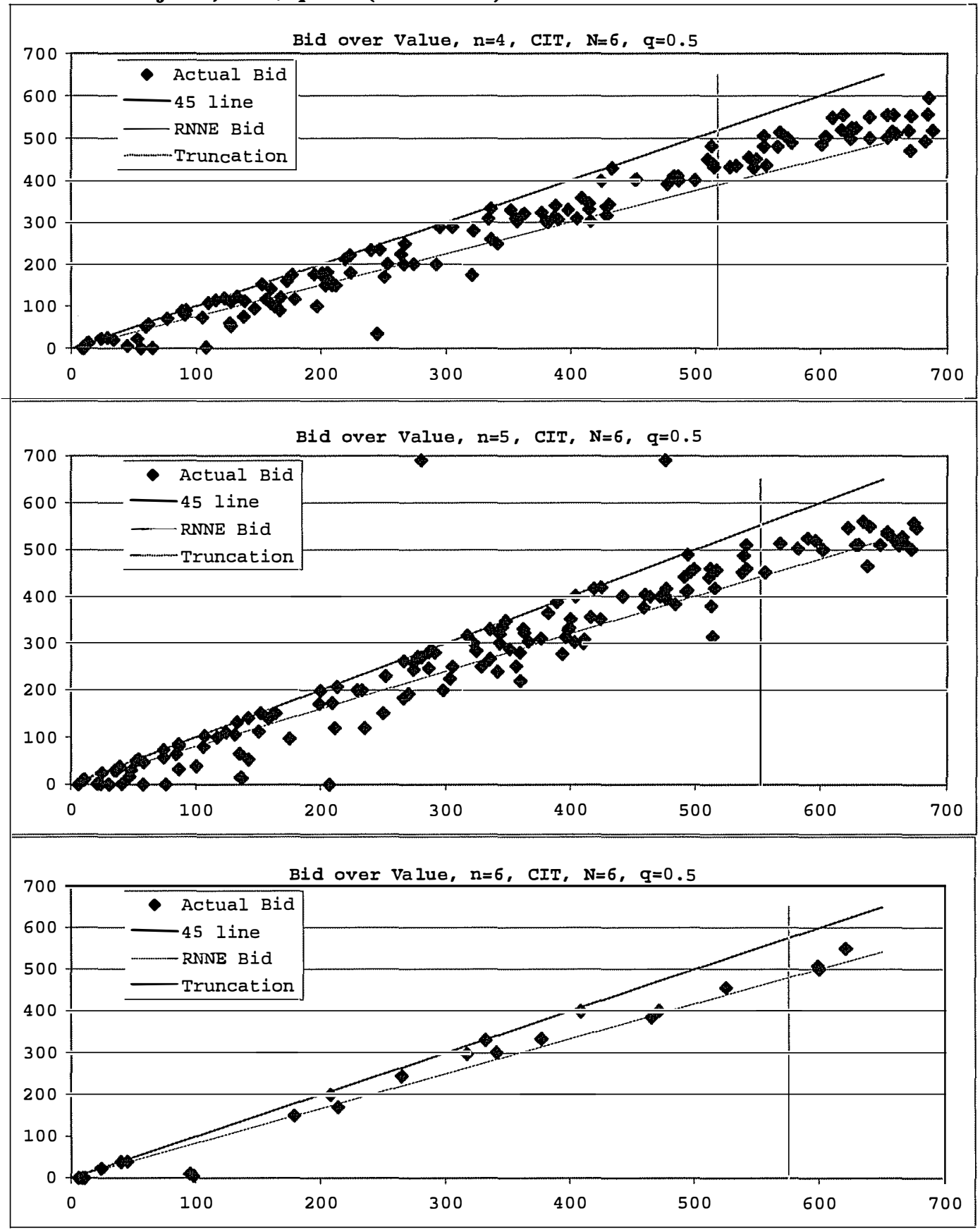
A.4. CIT subjects, $\mathrm{N}=6, \mathrm{w}=103, \mathrm{v}=691$.
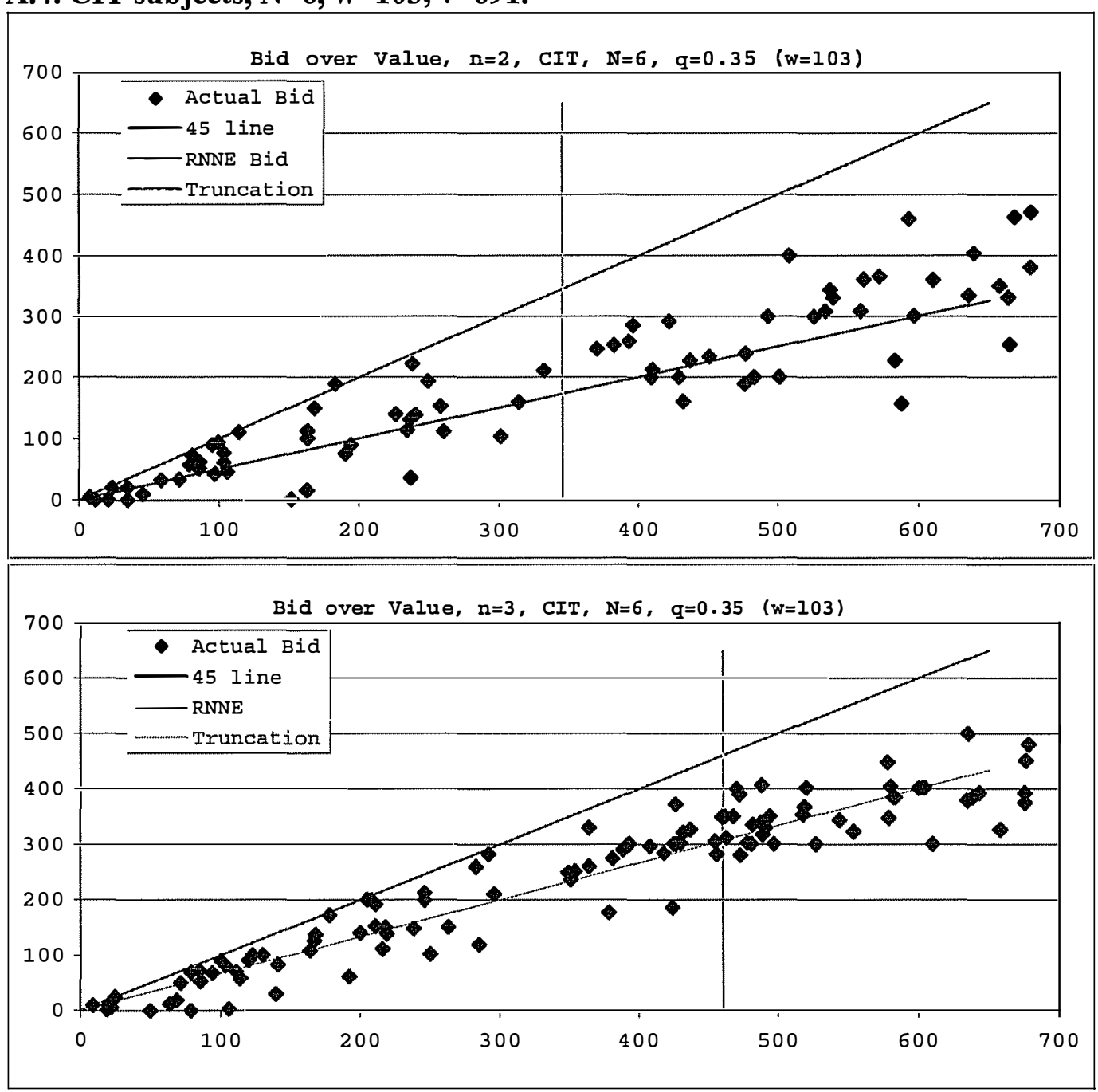
A.4. CIT subjects, $\mathrm{N}=6, \mathrm{q}=0.35$ (continued).

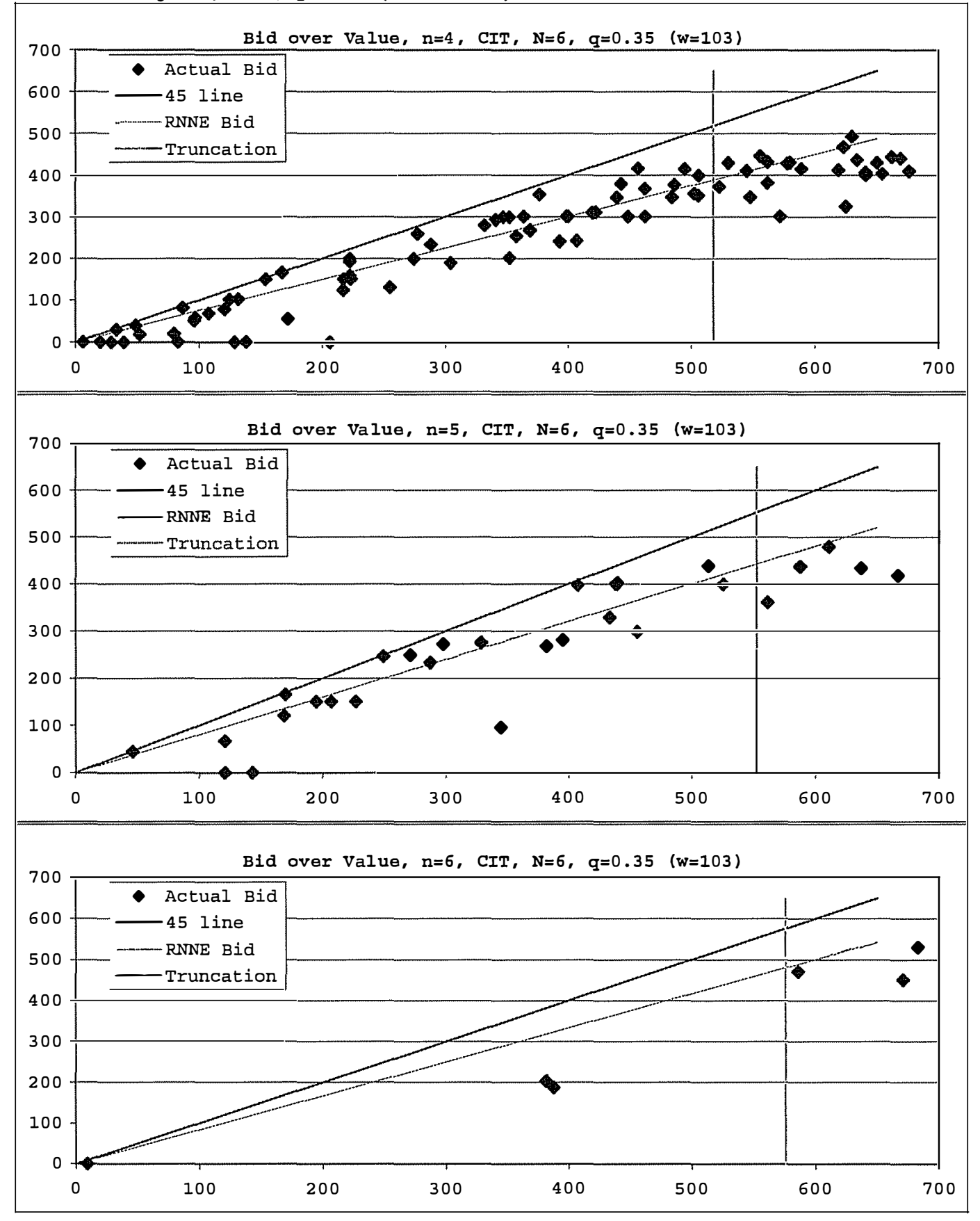


A.5. CIT subjects, no entry choice.
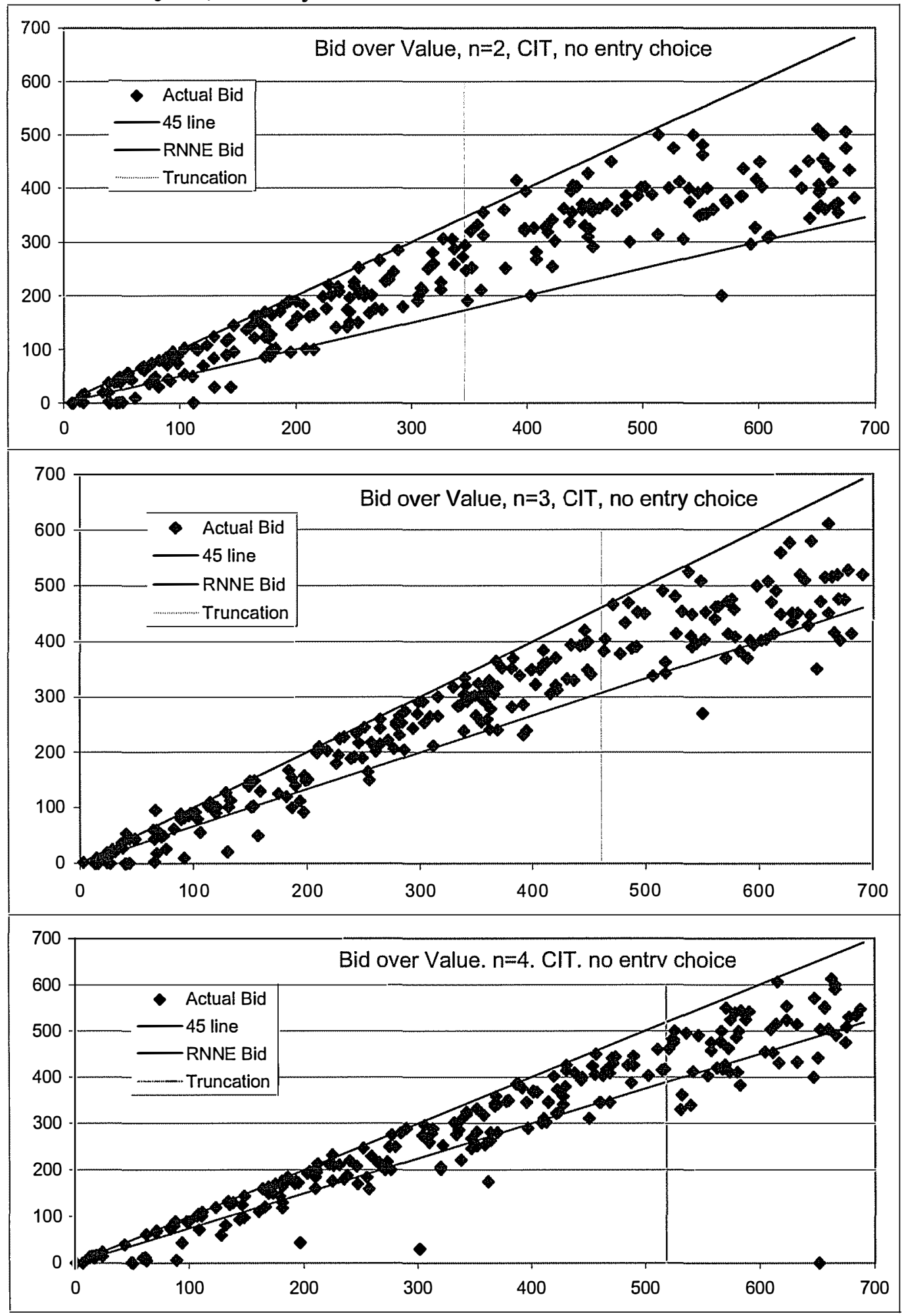


\section{Appendix B. Profits.}
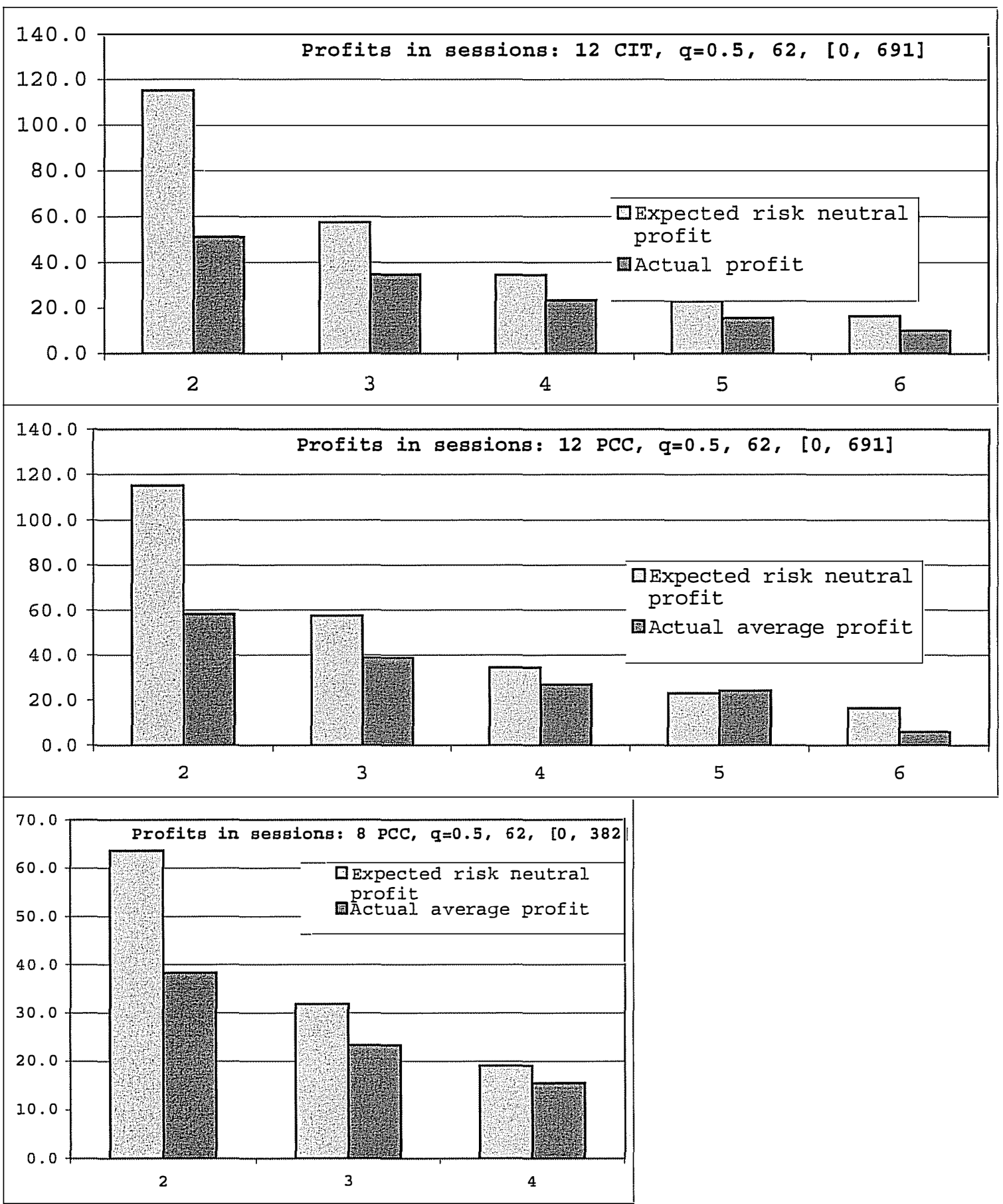


\section{Appendix C. Number of Subjects Entering the Auction at a Given Frequency}

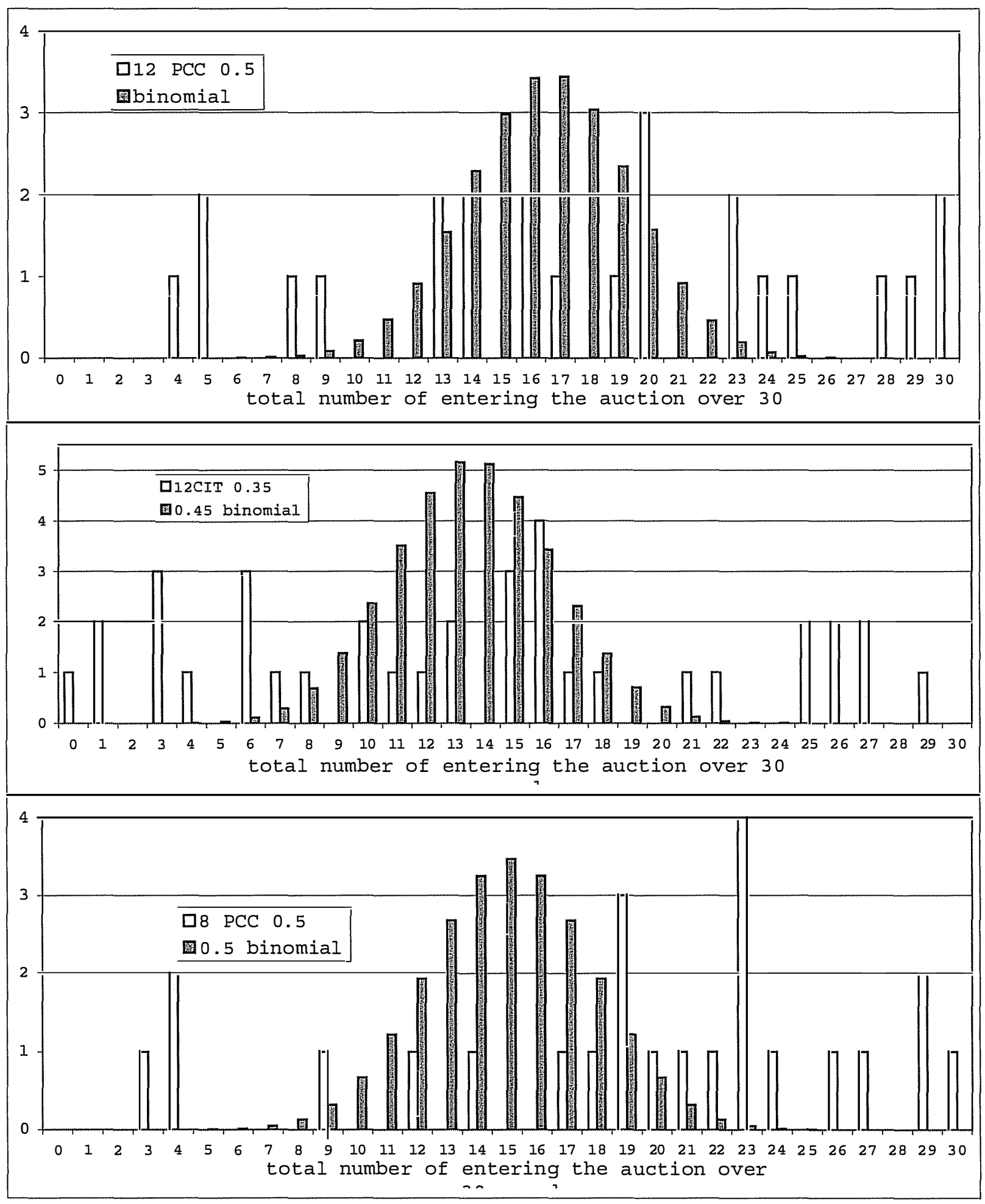




\section{Appendix D. Estimated bid-function slopes (OLS)}

(Observations with bids exceeding value, zero bids and data for non-liner part of bidding functions are excluded)

\begin{tabular}{|c|c|c|c|c|c|}
\hline Treatment & $\operatorname{In}$ & Slope & Error & $\mathrm{N}$ obs & $\mathrm{R}^{2}$ \\
\hline \multirow[t]{5}{*}{12 CIT $q=0.5$} & 2 & 0.680 & 0.047 & 15 & 0.94 \\
\hline & 3 & 0.830 & 0.042 & 47 & 0.90 \\
\hline & 4 & 0.870 & 0.022 & 102 & 0.94 \\
\hline & 5 & 0.888 & 0.020 & 125 & 0.94 \\
\hline & 6 & 0.949 & 0.048 & 18 & 0.96 \\
\hline \multirow[t]{5}{*}{12 CIT $q=0.35$} & 2 & 0.527 & 0.054 & 56 & 0.64 \\
\hline & 3 & 0.714 & 0.025 & 107 & 0.87 \\
\hline & 4 & 0.783 & 0.023 & 97 & 0.93 \\
\hline & 5 & 0.805 & 0.074 & 27 & 0.82 \\
\hline & 6 & 0.513 & 0.159 & 8 & 0.63 \\
\hline \multirow[t]{5}{*}{$12 \quad$ PCC $\quad q=0.5$} & 2 & 0.710 & 0.105 & 20 & 0.72 \\
\hline & 3 & 0.833 & 0.038 & 72 & 0.87 \\
\hline & 4 & 0.734 & 0.029 & 123 & 0.84 \\
\hline & 5 & 0.820 & 0.048 & 51 & 0.86 \\
\hline & 6 & 0.876 & 0.042 & 32 & 0.93 \\
\hline \multirow[t]{3}{*}{8 PCC $\quad q=0.5$} & 2 & 0.635 & 0.049 & 64 & 0.73 \\
\hline & 3 & 0.708 & 0.031 & 125 & 0.81 \\
\hline & 4 & 0.693 & 0.043 & 77 & 0.78 \\
\hline \multirow[t]{3}{*}{ Fixed-n } & 2 & 0.801 & 0.029 & 129 & 0.86 \\
\hline & 3 & 0.866 & 0.018 & 160 & 0.94 \\
\hline & 4 & 0.869 & 0.020 & 173 & 0.92 \\
\hline \multirow[t]{4}{*}{ Cox, Smith, walker } & 3 & 0.740 & 0.017 & 229 & 0.89 \\
\hline & 4 & 0.906 & 0.009 & 1007 & 0.91 \\
\hline & 5 & 0.949 & 0.015 & 232 & 0.95 \\
\hline & 6 & 0.869 & 0.012 & 324 & 0.94 \\
\hline
\end{tabular}




\section{Appendix E. Pearson chi-square test of goodness of fit in discrete}

\section{distributions.}

Rows: Frequency of entering the auction.

Columns: Confidence level for acceptance in each treatment

Result: the hypothesis of binomial distribution is rejected with 99\% confidence level 24 subjects in each dataset

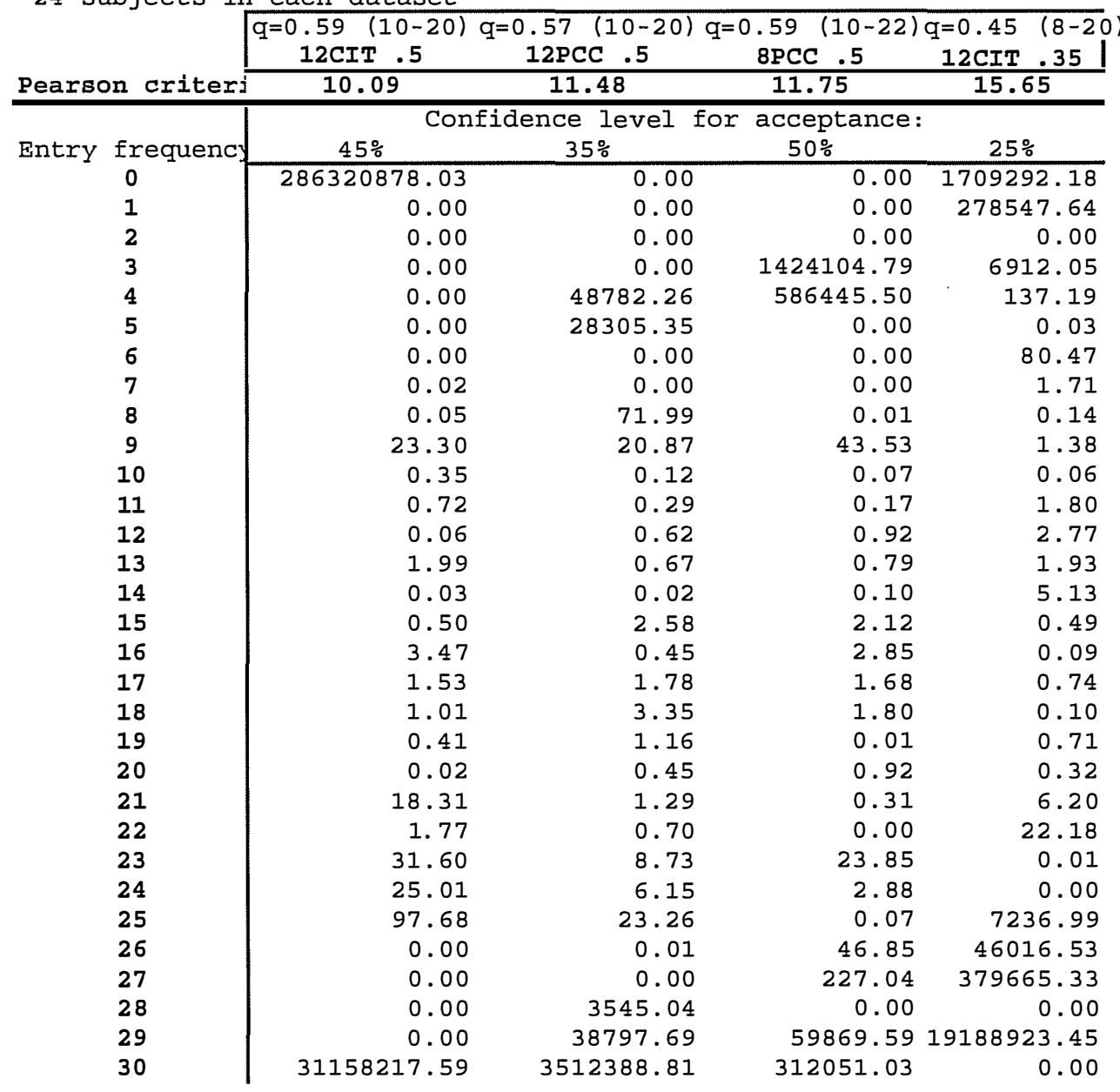




\section{Appendix F. Entry Frequency over Time.}

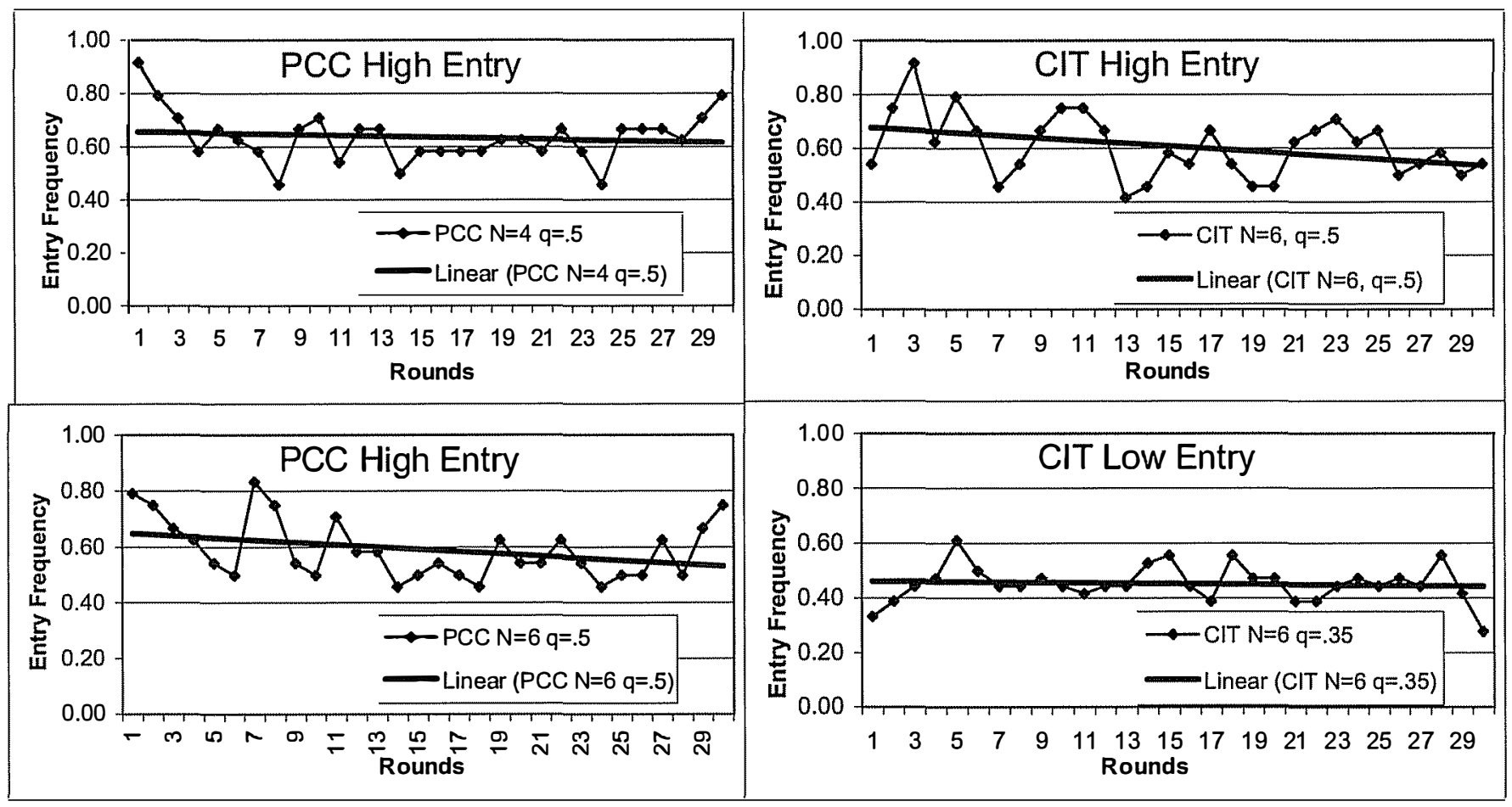

Entry Frequency $=$ Number of Bidders $/$ Number of Potential Bidders

\begin{tabular}{l|cccccccc}
\hline Treatments & Slope & Std. Error & $t$ Stat & P-value** & Intercept & Std. Error & $t$ Stat & P-value** \\
High Entry* & -0.00347 & 0.00136 & -2.556 & 0.02 & 0.665 & 0.0241 & 27.615 & 0.00 \\
4 PCC .5 & -0.00146 & 0.00203 & -0.722 & 0.48 & 0.659 & 0.0360 & 18.298 & 0.00 \\
6 PCC .5 & -0.00403 & 0.00216 & -1.867 & 0.07 & 0.653 & 0.0383 & 17.023 & 0.00 \\
6 CIT .5 & -0.00490 & 0.00234 & -2.097 & 0.05 & 0.683 & 0.0415 & 16.450 & 0.00 \\
6 CIT .35 & -0.00071 & 0.00144 & -0.494 & 0.63 & 0.464 & 0.0255 & 18.158 & 0.00 \\
\hline
\end{tabular}

* Includes all 3 treatments with High Entry Condition

** Shows the significance level. For 95\% significance level $P$-value $<0.05$ 


\section{Appendix G.}

\section{INSTRUCTIONS}

Welcome to the Experiment. Please do not do anything with the computer equipment until you are instructed to. Please put all of your personal belongings away, so we can have your complete attention. $<$ WAIT FOR SUBJECTS TO PUT BELONGINGS AWAY>

This is an experiment in decision making, and you will be paid for your participation in cash, at the end of the experiment. Different subjects may earn different amounts.

The entire experiment will take place through computer terminals, and all interactions will take place through the computers. It is important that you not talk or in any way try to communicate with other subjects during the experiment. If you disobey the rules, we will have to ask you to leave the experiment.

We will start with a brief instruction period. During this instruction period, you will be given a complete description of the experiment and will be shown how to eam money and how to use the computers. If you have any questions during the instruction period, raise your hand and your question will be answered so everyone can hear. If any difficulties arise after the experiment has begun, raise your hand, and an experimenter will come and assist you.

We will now pass out the experiment record sheets, on which you will record all of the results from the experiment. When you receive a record sheet, please write your name and social security number on top of the sheet. Raise your hand if you need a pencil.

\section{$<$ EXPERIMENTER PASS OUT EXPERIMENT RECORD SHEETS AND PENCILS> $<$ WAIT FOR SUBJECTS TO RECORD INFORMATION>}

The experiment will consist of a series of auctions that take place over rounds. There are participants today and in every round all subjects will be randomly divided into groups of _ person each. A separate auction will be held for each group in each round. A single object is offered in each of these auctions. In each round, before the auction begins, each of you will have the choice to participate in the bidding in your group's auction or not. If you choose not to participate in the auction, which we call the "OUT" option, you will receive a fixed payoff of francs for that round. For this experiment, each franc is worth exactly one cent, so this is equivalent to a payoff of cents. If you choose to participate in the auction, which we call the "IN" option, you will place a bid for the object. In each auction the object will be awarded to the highest bidder, with ties broken randomly.

To be more specific, if you choose to participate in your group's auction in a round, you will be randomly assigned a value for the object in that auction. Your value is the amount the object is worth to you. Your value will be determined by a random draw from to francs, with any value in between being equally likely. Therefore, different bidders will usually be assigned different values for the same object. You will be told your value before you make your bid, but you will not be told the value of the object to any other bidder in the auction. All you know is that each of their values is equally likely to be any number between and ___ francs. You will be told at this time exactly how many members of your group have chosen to participate in the auction. This number will be between 0 and _. If the number is 1 it means you are the only bidder, if the number is 2 , there is one more bidder besides you and so on.

After each bidder finds out their own value, you will place your bid. The bid must be between and _ francs. The object goes to the highest bidder. After all bidders have entered a bid, everyone is told what the high bid was for their group's auction. In the event of a tie the computer program will randomly choose which high bidder wins the object. If you win the object, your earnings are determined by subtracting your bid from your value. If you do not win the object, you eam zero in this auction. Notice that if you bid above your value and win an auction, your earnings will be negative and will be subtracted from your total. In order to have positive earnings your bid should be less that your value. <OVERHEAD: >

\section{$<$ Record Sheet Overhead $>$}

In the record sheet provided, if you choose to enter the auction you will record information about your value, your bid and number of bidders (columns $3,4,5$ ) as soon as it is given to you. If you choose not to enter the auction mark column 2 with an " $X$ ". In every round you need to record the number of bidders in the 
auction, the winning bid, your earnings in that round, and your cumulative earnings. You must do this even when you did not participate in the auction. Be sure to record all this information before proceeding to the next round.

We will conduct auctions like this over a sequence of rounds. At the beginning of each round, you will be randomly re-grouped by the computer, and you will not be told who is in your group in any round. If you choose the " $\mathrm{N}$ " option in several different rounds, your assigned value will usually be different, since they are reassigned every time by the random procedure. Your cash earnings for the experiment will be determined by adding up the eamings for each round. In addition you will be paid a $\$ 5.00$ show up fee for coming to the experiment.

\section{$<B E G I N$ COMPUTER INSTRUCTION SESSION>}

We will now begin the computer instruction session.

Please lower your chairs to the lowest position, and pull out the dividers as far as they will go. This ensures your privacy and the privacy of others in the experiment. During the computer instruction session, we will teach you how to use the computer by going through four practice rounds.

GET THEIR ATTENTION BEFORE READING THIS: Do not hit any keys until you are told to do so, and when you are told to enter information, please type exactly what you are told to type. You are not paid for these practice rounds.

Please click on the "Practice" icon to begin the computer program. We will now start the first practice round. For this practice round, we will have all subjects make the same choices. And we will tell you exactly what to do. In the real experiment you will all make your choices on your own.

Please enter your player number on the computer screen when prompted, and click OK. Your player number is written on the record sheet. Raise your hand if you need help getting started. Please wait for further instructions.

$$
<\text { WAIT FOR SUBJECTS TO ENTER NUMBER> }
$$

Please click once and wait. You now see the first experiment screen. You have a choice of entering the auction and participating in bidding (the "In" option) or not entering and getting specified payoff of francs (the "Out" option). Will all subjects now select the "IN" option.

$$
<\text { WAIT FOR SUBJECTS TO CLICK ON THE APPROPRIATE OPTION> }
$$

After everyone has made a decision, you will see the screen that shows the number of bidders who have chosen to participate in your auction and your value for the object in francs. Please record this information in the first row labeled "Practice". Since everyone was told to choose the " $\mathbb{N}$ " option in this case, the number of bidders should be __. Does everyone see it? In the real experiment, it could be any number from __ to __ depending on how many members of your group in that round choose the " $\mathbb{N}$ " option. There is a sliding scale below that allows you to choose a bid. Remember that your bid is subtracted from your value to determine your earnings if you win the auction. By moving it with the mouse right or left you can specify amount of the bid which is shown above the scale. You may change your bid one cent at a time by clicking on either the right or left arrows and the two ends of the scale. Please use the mouse to practice moving the scale left and right, and then choose a bid. Click to submit when you decide this is the bid you wish to make.

\section{$<$ WAIT FOR SUBJECTS TO SUBMIT CHOICE, CHECK THE BIDS >}

You now see the screen with the outcome of the auction. It shows your value, the number of bidders, your bid, the maximum bid and whether you have won the auction. The lower part of the screen shows your profit for this auction and your cumulative earning. Your cumulative earnings include this round and all previous rounds. Please record this information on your experiment record sheet in the first row labeled "Practice". Note that you leave column 2 blank.

\section{$<$ WAIT FOR SUBJECTS TO RECORD OUTCOME >}

You are not being paid for the practice session, but if this were real experiment, then the payoff would be money you have earned from this first round, in cents. We will now proceed to the second practice round. Please click the "Continue" button at this time.

\section{$<T H E$ SECOND PRACTICE ROUND STARTS>}

You have been randomly reassigned into new groups of for this second practice round. Remember that you are regrouped after every single round. Will all subjects choose the "Out" option at this time.

$$
<\text { WAIT FOR SUBJECTS TO CLICK ON THE APPROPRIATEOPTION> }
$$


Since nobody chose the "IN" option, the auction is over immediately. You now see the screen that shows number of bidders in the auction (0) and the maximum bid (0). Your eamings for this round are cents. Your cumulative eamings for the two practice rounds are also shown. Please record this information on your experiment record sheet in the second row labeled "PRACTICE".

$<T H E$ THIRD PRACTICE ROUND STARTS>

We will now proceed to the third practice round. Please click the "Continue" button at this time. Will all subjects with numbers 1-6 choose "In" and subjects with numbers 7-12 choose "Out". Please make your decision.

$$
<\text { WAIT FOR SUBJECTS TO CLICK ON THE APPROPRIATEOPTION> }
$$

If you have chosen the "In" option, record the number of bidders and your value and then go ahead and make your bid. If you have chosen the "Out" option, please wait for the end of the auction.

$$
<\text { WAIT FOR SUBJECTS TO SUBMIT CHOICE > }
$$

When the auction is over, record remaining information for this third round, but do not proceed to next round.

$$
<\text { WAIT FOR SUBJECTS TO RECORD OUTCOME> }
$$

In the next practice round you will be asked to choose the opposite option from what you have chosen in the third round. Please click "Continue" button at this time.

$<$ THE FOURTH PRACTICE ROUND STARTS>

Subjects with numbers 1-6 please choose "Out" now. Subjects with numbers 7-12 please choose "In" now.

$$
<\text { WAIT FOR SUBJECTS TO CLICK ON THE APPROPRIATEOPTION> }
$$

Please record the number of bidders and your value and make your bid. $<$ WAIT FOR SUBJECTS TO SUBMIT CHOICE $>$

When the round is over please record the rest of information in the fourth row labeled "Practice". $<$ WAIT FOR SUBJECTS TO RECORD OUTCOME>

Please click the "Continue" button at this time. This concludes practice rounds. The computer screen now indicates your total payoff for the two practice rounds. You will not be paid for these practice rounds; this is the amount you would have earned for these rounds if they were rounds in the actual experiment.

Are there any questions?

$$
\text { <EXPERIMENTER TAKE QUESTIONS> }
$$

We will now pass out a short quiz that reviews the rules of this experiment. Please take a minute to fill the answers. Place the quiz face down on your monitor when you have finished.

<EXPERIMENTER PASS QUIZ,CLEAR SUBJECTS SCREEN, WAIT FOR SUBJECTS TO ANSWER>

$$
<\text { EXPERIMENTER GOES OVER THE QUIZ> }
$$

O.K., then we will now begin the actual experiment. If there are any problems from this point on, raise your hand and an experimenter will come and assist you in private. Is everyone ready?

Okay, we will now begin round number 1. Please click on the "Auction" icon to begin the program. Do not click on "Practice". Please enter your player number when prompted by the computer. Remember to record all the information in each round on your record sheet before continuing on to the next round.

$$
<\text { START EXPERIMENT > }
$$

The experiment is over. Please record your total earnings in the record sheet and wait. We will call you to be paid in the order of your subject number. Please do not use computers or talk with the other subjects while you are waiting. Thank you for your participation. 